\title{
A new species group and five new species of the genus Pavania (Acari: Dolichocybidae) associated with insects, with notes on leg chaetotaxy and the distribution of genera
}

\author{
HamidreZa HAJIQANBAR ${ }^{1}$ and AleXnder KHAUSTOV ${ }^{2}$ \\ ${ }^{1}$ Department of Entomology, Faculty of Agriculture, Tarbiat Modares University, 14115-336, Tehran, Iran; \\ e-mail: hajiqanbar@modares.ac.ir \\ ${ }^{2}$ Nikita Botanical Gardens, National Scientific Center, Yalta, Crimea, 98648, Ukraine; e-mail: alkhaustov@mail.ru
}

Key words. Acari, Prostigmata, Heterostigmata, Dolichocybidae, Pavania, taxonomy, new species, chaetotaxy, Coleoptera, Scarabaeidae, Carabidae, Iran

\begin{abstract}
A new species group and five new species of mites of the genus Pavania Lombardini, 1949 belonging to the family Dolichocybidae (Acari: Heterostigmata) are described from Iran. Pavania gymnopleuri Hajiqanbar \& Khaustov sp. n., P. sabzevarensis Hajiqanbar \& Khaustov sp. n. and P. onthophagi Hajiqanbar \& Khaustov sp. n., represent a new gymnopleuri species group. Two new species are also described in the fusiformis group: P. kamalii Hajiqanbar \& Khaustov sp. n. and P. elongata Hajiqanbar \& Khaustov sp. n. All new species are associated with scarabaeid and carabid beetles (Coleoptera: Scarabaeidae, Carabidae). This is the first record of the family Dolichocybidae from Iran. The leg setation and geographic distribution of all genera of this family are discussed and keys to genera and species of the genus Pavania are provided.
\end{abstract}

\section{INTRODUCTION}

In the section Heterostigmata, according to Mironov \& Bochkov (2009), the basal superfamily Dolichocyboidea includes the families Dolichocybidae Mahunka, 1970 and Crotalomorphidae Lindquist \& Krantz, 2002 (Lindquist \& Krantz, 2002). Despite this, these mites are morphologically and biologically specialized. Mites of the family Dolichocybidae are associated with different insects, especially beetles and ants with which the female mites have a phoretic relationship. Parasitic associations are not recorded in this family. The adult females are fungivorous and demonstrate the phenomenon of neosomy (Kaliszewski et al., 1995) in which the larvae and males live within the body of the physogastric females; males are therefore poorly known.

Hitherto, this family consisted of two subfamilies, six genera and 30 species and was not recorded in Iran. During an extensive survey of the insect-associated heterostigmatic mites in northeastern Iran, five new species of the genus Pavania, belonging to the family Dolichocybidae, were recorded and are described here. In this paper, we establish a new gymnopleuri species group containing 3 new species within the genus Pavania. Pavania is thus divided into two species groups: the fusiformis group (based on the name for the type species) containing 15 species including two additional new species described below, and the gymnopleuri group containing 3 species.

\section{MATERIAL AND METHODS}

Mites were collected from different species of the beetle families Scarabaeidae and Carabidae (Insecta: Coleoptera). Of the host beetles, some were captured in a light trap but most were collected directly in their habitats, i.e., livestock dung pads.

The mites were cleared in lactophenol and mounted in Hoyer's medium. Morphology of the mites was studied using a light microscope with phase contrast. All measurements in the descriptions are given in micrometers for the holotype and (when available) for five paratypes (in parentheses). Terminology follows that of Lindquist (1986). Details of geographical coordinates were recorded using a GPS mobile device. The scarabaeid beetle hosts were identified by V. Martynov (Donetsk National University, Donetsk, Ukraine).

Holotypes of new taxa are deposited in the Acarological Collection, Department of Entomology, Faculty of Agriculture, Tarbiat Modares University, Tehran, Iran. One paratype of each species is deposited in the following collections: Zoological Institute, University of Hamburg, Hamburg, Germany; U.S. National Museum of Natural History, Washington D.C., U.S.A.; Collection of Nikita Botanical Gardens, Yalta, Ukraine; Department of Animal Taxonomy and Ecology, A. Mickiewicz University, Poznan, Poland; and Acarological Collection, Zoological Museum, College of Agriculture, University of Tehran, Karaj, Iran. Most paratypes are retained with the holotype.

\section{SYSTEMATICS}

Family Dolichocybidae Mahunka, 1970

\section{Genus Pavania Lombardini, 1949}

Type species: Pavania fusiformis Lombardini, 1949

Diagnosis of adult female

Gnathosoma. Gnathosoma rounded subquadrangular, usually longer than wide; dorsally with 2 pairs of cheliceral setae $\left(c h_{1}\right.$ and $\left.c h_{2}\right)$ and ventrally with 1 pair of subcapitular setae $(s u)$. Cheliceral stylets large and sickle-shaped. Pharynx hardly visible, rounded. Palpi originated ventrolaterally from gnathosoma, 2-segmented. 

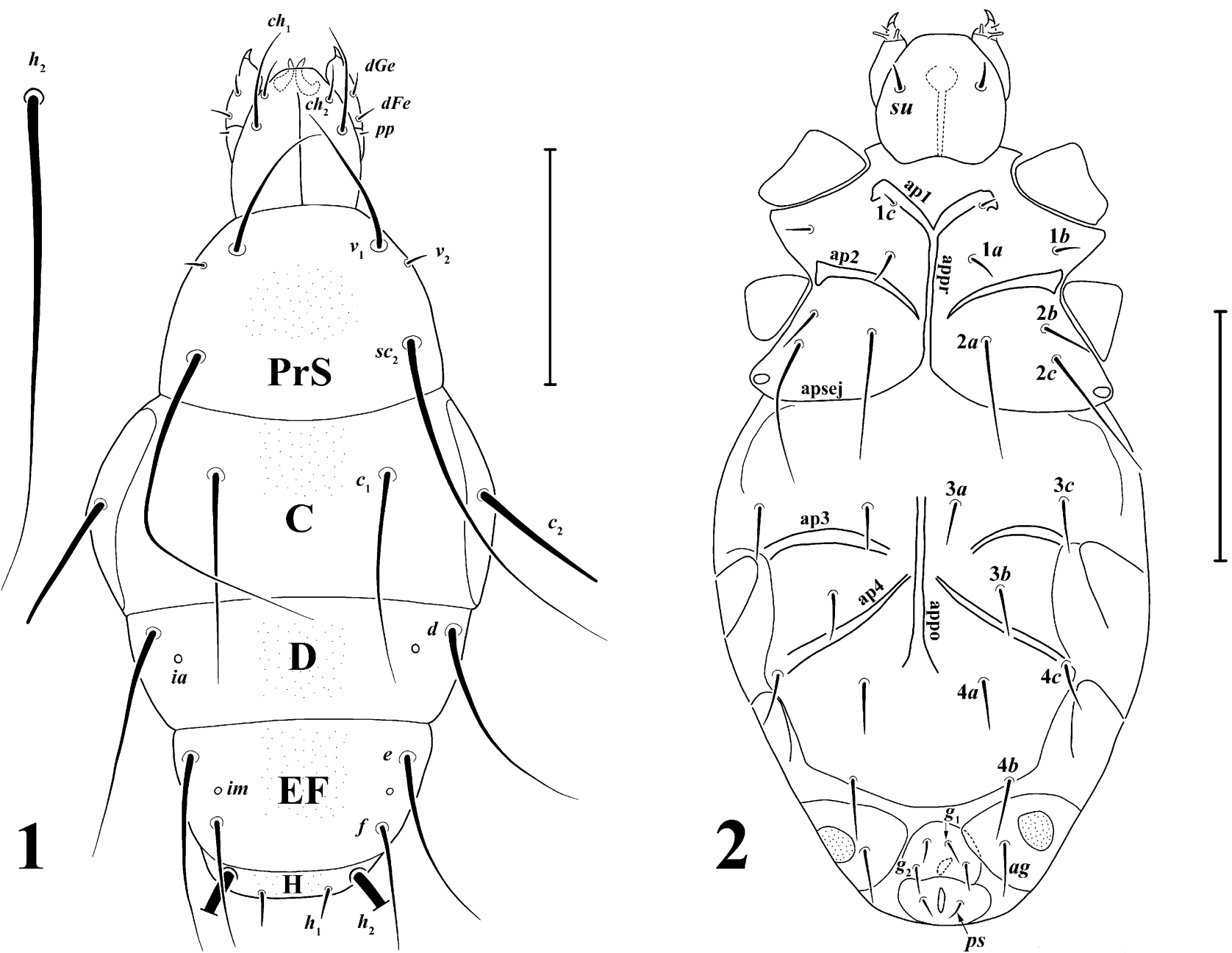

Figs 1-2. Pavania gymnopleuri sp. n., female. 1 - body in dorsal view; 2 - body in ventral view. Scale bars $50 \mu \mathrm{m}$.

Palpal tibiotarsus with 2 solenidia and a small seta, terminated in a distinct claw. Palpal femurogenu with 2 dorsolateral setae $(d G e$ and $d F e)$. Small palpcoxal seta $(p p)$ evident at palp bases.

Idiosoma. Sometimes with tiny dimples on dorsal surface. Prodorsum with 3 pairs of setae $\left(v_{1}, v_{2}\right.$ and $\left.s c_{2}\right)$, setae $v_{2}$ shorter than $s c_{2}$ and $v_{1}$; trichobothridia $\left(s c_{1}\right)$ present or absent. Posterior edges of tergites undulated in some species. Cupuli ia and im obvious on tergites D and EF, respectively. Ventral apodemes usually welldeveloped; apodeme I (ap1) joined to the presternal apodeme (appr) forming a Y-shaped structure. Each coxisternal plate with 3 pairs of setae; setae $3 a$ and $3 c$ situated out of third coxisternal plate and inserted above apodemes III. Genital plate with 2 pairs of setae $\left(g_{1}\right.$ and $\left.g_{2}\right)$ and genital aperture. Aggenital plates spaced and flanking genital plate, and each bearing one seta ( $a g)$ and a small porous area. Pseudanal plate with one pair of setae ( $p s)$ and anal slit. Legs. Leg I thicker than other legs, legs II-IV similar in shape, 5-segmented, all with empodium and paired claws, without spine-like setae and all solenidia emergent. Number of setae and solenidia on each leg: Leg I: Fe 4 (d, v', l', l’'); Ge 2 (v', l'); Ti 6 (d,

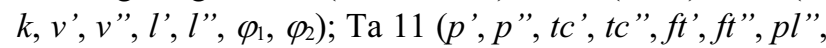
$\left.p v^{\prime}, p v^{\prime \prime}, u^{\prime}, u^{\prime \prime}, \omega_{1}, \omega_{2}\right)$. Leg II: Fe $2\left(d, v^{\prime \prime}\right)$; Ge $1\left(l^{\prime}\right)$; Ti $4\left(d, v^{\prime}, v^{\prime \prime}, l^{\prime}, \varphi\right)$; Та 6 (tc',tc”, $\left.p v^{\prime}, p v^{\prime \prime}, p l l^{\prime \prime}, u^{\prime}, \omega\right)$. Leg III: Fe $1(d)$; Ge $1\left(v^{\prime}\right)$; Ti $4\left(d, v^{\prime}, v^{\prime \prime}, l^{\prime}\right)$; Ta 5 (tc', tc", $p v^{\prime}, p v^{\prime \prime}, p l$ '). Leg IV: Fe $1(d)$; Ge $1\left(v^{\prime}\right)$; Ti $4\left(d, v^{\prime}, v^{\prime \prime}\right.$, $\left.l^{\prime}\right)$; Ta 5 ( $\left.t c^{\prime}, t c^{\prime \prime}, p v^{\prime}, p v^{\prime \prime}, p l^{\prime \prime}\right)$.

Male unknown.

The genus Pavania is here divided in two species groups:

Pavania gymnopleuri species group (Figs 1-18): Prodorsum only with 3 pairs of setae $\left(v_{1}, v_{2}\right.$ and $\left.s c_{2}\right)$, trichobothridia $\left(s c_{1}\right)$ absent.

Pavania fusiformis species group (Figs 19-30): Prodorsum with 3 pairs of setae $\left(v_{1}, v_{2}\right.$ and $\left.s c_{2}\right)$ and one pair of capitate trichobothridia $\left(s c_{1}\right)$.

\section{Pavania gymnopleuri species group}

Pavania gymnopleuri Hajiqanbar \& Khaustov sp. n.

(Figs 1-6)

Differential diagnosis. The new species resembles two other species of this species group: P. sabzevarensis and $P$. onthophagi. Readily recognizable from these two species by the following characters: gnathosoma with cheliceral setae $c h_{1}$ nearly 3 times longer than $c h_{2}$ (1.7 times in $P$. sabzevarensis and 1.5 times in $P$. onthophagi); dorsal idiosomal setae smooth and pointed except $c_{2}$ which is blunt-ended $\left(c_{2}, e\right.$ and $f$ blunt-ended in $P$. sabzevarensis 
and most dorsal idiosomal setae weakly barbed and distinctly blunt-ended in $P$. onthophagi); seta $e$ longer than $f$ (e shorter than $f$ in $P$. sabzevarensis and $e$ almost as long as $f$ in $P$. onthophagi); seta $h_{2}$ almost 15 times longer than $h_{1}$ (7 times in P. sabzevarensis and nearly 3.5 times in $P$. onthophagi); ventral idiosomal setae smooth, attenuated and pointed, setae $2 a$ and $2 c$ longest on ventral aspect (ventral idiosomal setae smooth and needle-like, setae $2 a$ longest on the ventral aspect of both $P$. sabzevarensis and P. onthophagi).

\section{Description}

Female (holotype). Length of idiosoma 144 (140-147 in 5 paratypes), width 86 (85-91).

Gnathosoma (Figs 1-2). Length of gnathosoma 31 (28-31), width 28 (27-28). Gnathosomal capsule rounded subquadrangular in dorsal aspect, slightly longer than wide; cheliceral setae $c_{1} 25$ (21-23) and $c_{2} 9$ (9-12) pointed and smooth. Dorsomedian apodeme evident and forming the longitudinal division in dorsal view of gnathosomal capsule. Cheliceral stylets 10 (9-11) long, curved and sickle-shaped. Subcapitulum with subcapitular setae su 7 (6-7) stiff, located on anterior half. Pharynx situated between subcapitular setae. Palpi conspicuous, exceeding apex of gnathosomal capsule, femorogena with setae $d G e 5$ (5-7) and $d F e ~ 4$ (4-5), tibiotarsus with 2 solenidia, one longer than the other; minute palpcoxal setae $p p$ inserted near to articulation of each palp with gnathosomal capsule.

Idiosomal dorsum (Fig. 1). Ovoid in shape. All dorsal shields with smooth posterior margins, ornamented with sparse dimples, without backward undulating projections. All dorsal idiosomal setae smooth. Prodorsal shield (PrS) subtrapezoid, anterior margin approximately straight, posterior margin concave, with setae $v_{1} 35$ (31-37), $v_{2} 5$ (4-5), $s c_{2} 78$ (77-84), setae $v_{1}$ longer than distance between their bases, both $v_{1}$ and $s c_{2}$ tapered and pointed, $v_{2}$ very short and located posterolaterally to $v_{1}$. Median shield of tergite $\mathrm{C}$ bearing setae $c_{1} 47$ (45-46) tapered and pointed and each lateral shield with 1 distinctly bluntended seta $c_{2} 29$ (28-33), $c_{1}$ almost 1.6 times longer than $c_{2}$. Tergite $\mathrm{D}$ with setae $d 50(48-55)$ tapered and pointed and cupuli $i a$ situated posterolaterally to setae $d$ on each side, setae $c_{1}$ and $d$ subequal in length. Tergite EF with setae $e 45$ (38-43), $f 27$ (28-30) tapered and pointed, and 1 pair of cupuli im placed between insertion of setae $e$ and $f$, seta $e$ nearly 1.7 times longer than $f$. Tergite $\mathrm{H}$ with setae $h_{1} 7$ (6-8) needle-like and $h_{2} 108$ (106-111) ultralong, attenuated and pointed; seta $h_{2}$ approximately 15 times longer than $h_{1}$. Distances between dorsal idiosomal setae: $v_{1}-v_{1} 30$ (29-30), $v_{2}-v_{2} 43$ (40-41), $v_{1}-v_{2} 6$ (6-6), $s c_{2}-s c_{2} 49$ (47-47), $c_{1}-c_{1} 34$ (33-36), $d-d 62$ (59-66), e-e 46 (45-48), f-f 35 (36-38), e-f 16 (13-17), $h_{1}-h_{1} 13$ (11-13), $h_{2}-h_{2} 28$ (28-29), $h_{1}-h_{2} 7$ (6-8).

Idiosomal venter (Fig. 2). Ventral idiosomal setae smooth, attenuated and pointed, setae $2 a$ and $2 c$ longest on ventral aspect. Apodemes II (ap2) not reaching to presternal apodeme (appr); both apodemes III (ap3) and IV (ap4) not joined to poststernal apodeme (appo). Coxal field I: $1 a 5(5-5), 1 b 5(5-5), 1 c 4(4-5), 1 a$ and $1 b$
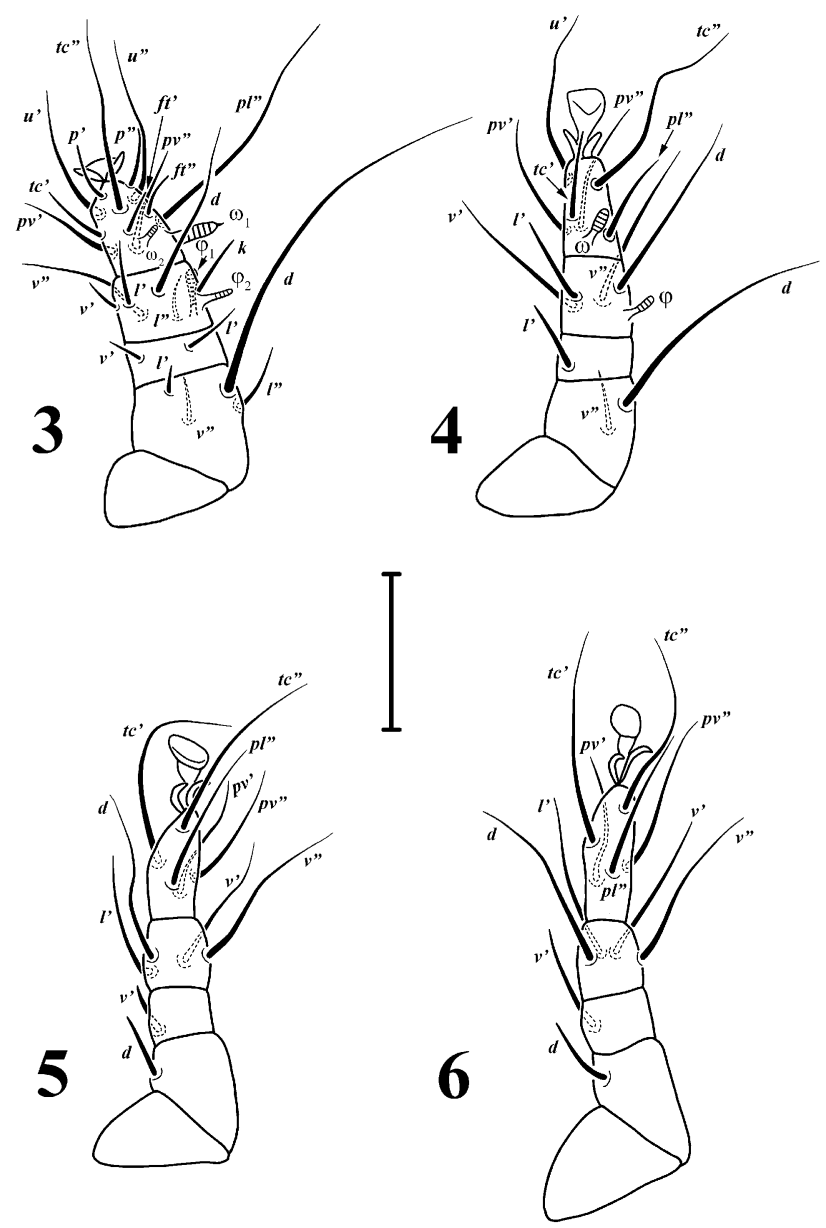

Figs 3-6. Pavania gymnopleuri sp. n., female: legs I-IV in dorsal view, respectively. Scale bar $20 \mu \mathrm{m}$.

subequal in size and slightly longer than $1 c$. Coxal field II: $2 a 27$ (23-25), $2 b 11$ (9-10), 2c 30 (27-29), seta $2 c$ longer than $2 a$ and both more than 2 times longer than $2 b$. Coxal field III: $3 a 10$ (8-9), $3 b 10$ (9-10), 3c 11 (10-11), all subequal in size. Coxal field IV: $4 a 10$ (9-11), $4 b 12$ $(11-13), 4 c 10(10-12)$, setae $4 a$ and $4 c$ of the same length and shorter than $4 b$. Genital plate with setae $g_{1} 4$ (4-5), $g_{2} 5$ (4-6). Aggenital plates each bearing seta $a g$ $10(9-11)$ and 1 small porous area. Pseudanal plate with setae ps 5 (5-6).

Legs (Figs 3-6). Leg I (Fig. 3): setal formula (number of solenidia in parentheses): 4-2-6(2)-11(2). Tarsus with 4 slightly blunt-ended eupathidial setae $p$ ', $p$ ", $f t$ ' and $f t$ ", rest of setae on the leg I seta-like and pointed; $p l$ "' longest seta on tarsus; solenidion $\omega_{1} 6$ (5-6) prominent, finger shaped and stalked with a fine apical spine; solenidion $\omega_{2}$ 3 (3-3) finger shaped. Tibia with eupathidium $k$ stiff, thicker than other setae; solenidion $\varphi_{1} 6$ (6-7) fairly clubbed and stalked, longer than finger shaped $\varphi_{2} 4$ (3-4). Genu with 2 setae ( $l$ ' and $\left.v^{\prime}\right), l^{\prime}$ approximately twice as long as $v^{\prime}$. Seta $d$ on femur longer than leg I; seta $l$ ", longer than $v^{\prime \prime}$.

Leg II (Fig. 4). Setal formula: 2-1-4(1)-6(1). Setae of leg attenuated and pointed except setae $l$ ' on the genu and $v$ " on femur, which are needle-like, $t c$ ' and $t c$ " shortest and longest setae on tarsus, respectively, solenidion $\omega 5$ 

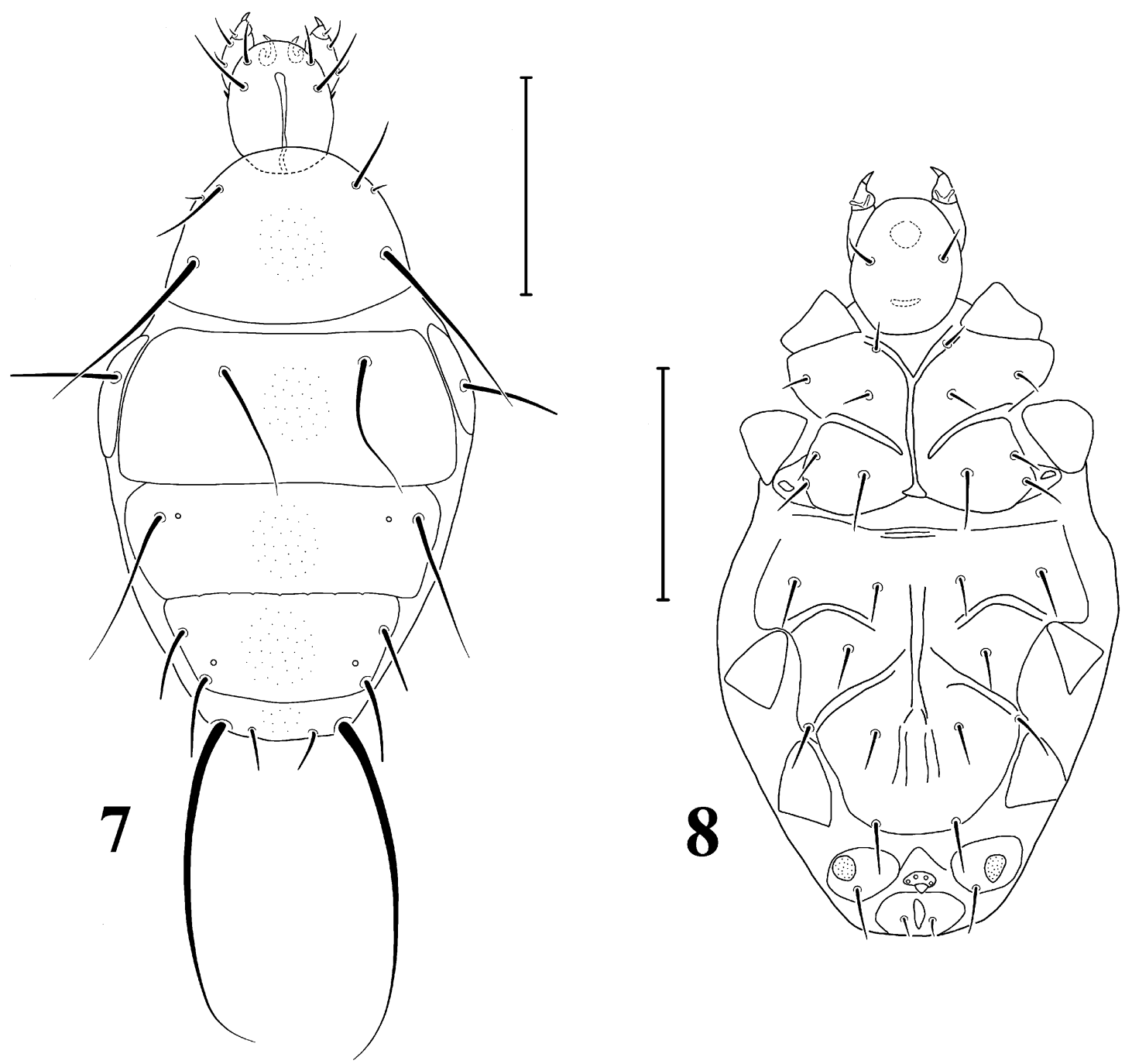

Figs 7-8. Pavania sabzevarensis sp. n., female. 7 - body in dorsal view; 8 - body in ventral view. Scale bars $50 \mu \mathrm{m}$.

(4-5) finger shaped, stalked and striated; solenidion $\varphi 4$ (4-4) similar to $\omega$ but thinner; seta $d$ on femur longest seta of the leg II and 4 times as long as seta $v$ ”.

Leg III (Fig. 5). Setal formula: 1-1-4-5. Setae of leg attenuated and pointed except setae $v$ ' on genu and $d$ on femur, which are needle-like; seta $d$ of femur longer than seta $v$ ' of genu; setae $d$ and $v$ " subequal in length and seta $d$ longer than $l$ ' on tibia.

Leg IV (Fig. 6). Setal formula: 1-1-4-5. Setae of leg attenuated and pointed except setae $v^{\prime}$ on genu and $d$ on femur, which are needle-like; seta $v$ ' of genu longer than seta $d$ of femur; on tibia setae $d$ and $v$ "' subequal in length and seta $d$ more than twice as long as this segment.

Male unknown.

Type material. Holotype $\uparrow($ Sab-2-I) and $14 \uparrow$ paratypes, phoretic on Gymnopleurus mopsus persianus Reitter, 1893 (Coleoptera: Scarabaeidae) collected in dung pads of livestock: Northeastern Iran, Razawi Khorasan province, Mehr village in the vicinity of Sabzevar town, $36.30^{\circ} \mathrm{N}, 57.80^{\circ} \mathrm{E}$, altitude 1,024 m, 4.vi.2007, coll. H. Hajiqanbar.

Etymology. The name gymnopleuri refers to the generic name of the scarab host - Gymnopleurus.

\section{Pavania sabzevarensis Hajiqanbar \& Khaustov sp. n.}

(Figs 7-12)

Differential diagnosis. The new species differs from two other species of this species group in its cheliceral setae $c h_{1}$, which are nearly 1.7 times longer than $c h_{2}(3$ times in $P$. gymnopleuri and 1.5 times in $P$. onthophagi); dorsal idiosomal setae smooth and pointed except $c_{2}, e$ and $f$, which are blunt-ended ( $c_{2}$ blunt-ended in P. gymnopleuri and most dorsal idiosomal setae weakly barbed and distinctly blunt-ended in $P$. onthophagi); seta $e$ shorter than $f$ (e longer than $f$ in $P$. gymnopleuri and $e$ almost as long as $f$ in $P$. onthophagi); seta $h_{2} 7$ times longer than $h_{1}$ (almost 15 times in $P$. gymnopleuri and nearly 3.5 times in $P$. onthophagi); ventral idiosomal setae smooth and needle-like, setae $2 a$ the longest ones on the ventral aspect (the same in $P$. onthophagi but ventral idiosomal setae smooth, attenuated and pointed, setae $2 a$ and $2 c$ the longest on ventral aspect in $P$. gymnopleuri); genu I with one seta $v^{\prime}$ (with two setae $v^{\prime}$ and $l^{\prime}$ in both $P$. gymnopleuri and $P$. onthophagi). 


\section{Description}

Female (holotype). Length of idiosoma 126 (114-122 in 5 paratypes), width 83 (78-81).

Gnathosoma (Figs 7-8). Length of gnathosoma 29 (29-30), width 25 (23-25). Gnathosomal capsule rounded subquadrangular in dorsal aspect, longer than wide; cheliceral setae $c h_{1} 15$ (13-17) and $c h_{2} 9$ (9-11) needle-like. Dorsomedian apodeme evident. Cheliceral stylets 9 (7-9) curved and falcate. Subcapitulum with subcapitular setae $s u 7$ (6-7) stiff and located on anterior half. Palpi conspicuous, exceeding apex of gnathosomal capsule, femorogenu with setae $d G e \quad 6(6-7)$ and $d F e ~ 4$ (4-5), tibiotarsus with 2 solenidia, subequal in size; minute palpcoxal setae $p p$ inserted near to articulation of each palp on gnathosomal capsule.

Idiosomal dorsum (Fig. 7). Ovoid in shape. All dorsal shields ornamented with sparse dimples; some specimens with deep and large dimples limited to margins of prodorsum and tergites $\mathrm{C}$ and $\mathrm{D}$; in some specimens posterior margins of some shields with backward undulating projections. All dorsal idiosomal setae smooth. Prodorsal shield subtrapezoid, with anterior margin curved and concave posterior margin, with setae $v_{1} 17(15-17), v_{2} 4$ (4-5), $s c_{2} 45$ (45-50), setae $v_{1}$ shorter than distance between their bases, both $v_{1}$ and $s c_{2}$ tapered and pointed, $v_{2}$ very short and located posterolaterally to $v_{1}$. Median shield of tergite $C$ including setae $c_{1} 32$ (30-33) tapered and pointed and each lateral shield with 1 blunt-ended seta $c_{2} 25$ (22-23), $c_{1}$ approximately 1.3 times longer than $c_{2}$. Tergite D bearing setae $d 33$ (30-34) tapered and pointed, and cupuli $i a$ situated laterally to seta $d$, setae $c_{1}$ and $d$ subequal in length, posterior margin of tergite $\mathrm{D}$ with seven equally spaced tiny projections. Tergite EF with blunt-ended setae $e 16$ (15-17), $f 18$ (17-20) and 1 pair of cupuli im placed anterolaterally to setae $f$, seta $f$ slightly longer than $e$. Tergite $\mathrm{H}$ with setae $h_{1} 10(10-11)$ needle-like and $h_{2} 72$ (72-77) ultra-long, attenuated and pointed; seta $h_{2}$ almost 7 times as long as $h_{1}$. Distances between dorsal idiosomal setae: $v_{1}-v_{1} 29$ (26-29), $v_{2}-v_{2}$ 37 (35-38), $v_{1}-v_{2} 4$ (4-5), sc $-s c_{2} 43$ (40-43), $c_{1}-c_{1} 30$ (30-33), $d-d 57$ (57-58), e-e 44 (44-46), f-f 34 (33-36), $e-f 10(11-12), h_{1}-h_{1} 13(11-12), h_{2}-h_{2} 26(25-26), h_{1}-h_{2}$ $6(5-7)$.

Idiosomal venter (Fig. 8). All ventral idiosomal setae smooth and needle-like; some specimens with deep and large dimples limited to margins of coxal fields. Apodemes II not reaching to presternal apodeme; both apodemes III and IV not joined to the poststernal apodeme. Coxal field I with $1 a 6$ (6-7), $1 b 5$ (5-7), $1 c 5$ (5-6), both latter subequal in size and slightly shorter than $1 a$. Coxal field II with $2 a 12$ (10-12), $2 b 7$ (6-7), $2 c 10$ (9-11), seta $2 a$ approximately 2 times as long as $2 b$. Coxal field III with $3 a 9$ (9-10), $3 b 9(8-10), 3 c 11(10-11)$, setae $3 a$ and $3 b$ sub-equal in length and both shorter than $3 c$. Coxal field IV with $4 a 8$ (8-9), $4 b 11$ (10-11), $4 c 9$ (9-10), $4 b$ longer than $4 a$ and $4 c$. Genital plate without setae $g_{1}$ and $g_{2}$ (only their alveoli remain) but genital aperture visible. Aggenital plates each bearing 1 seta $a g$
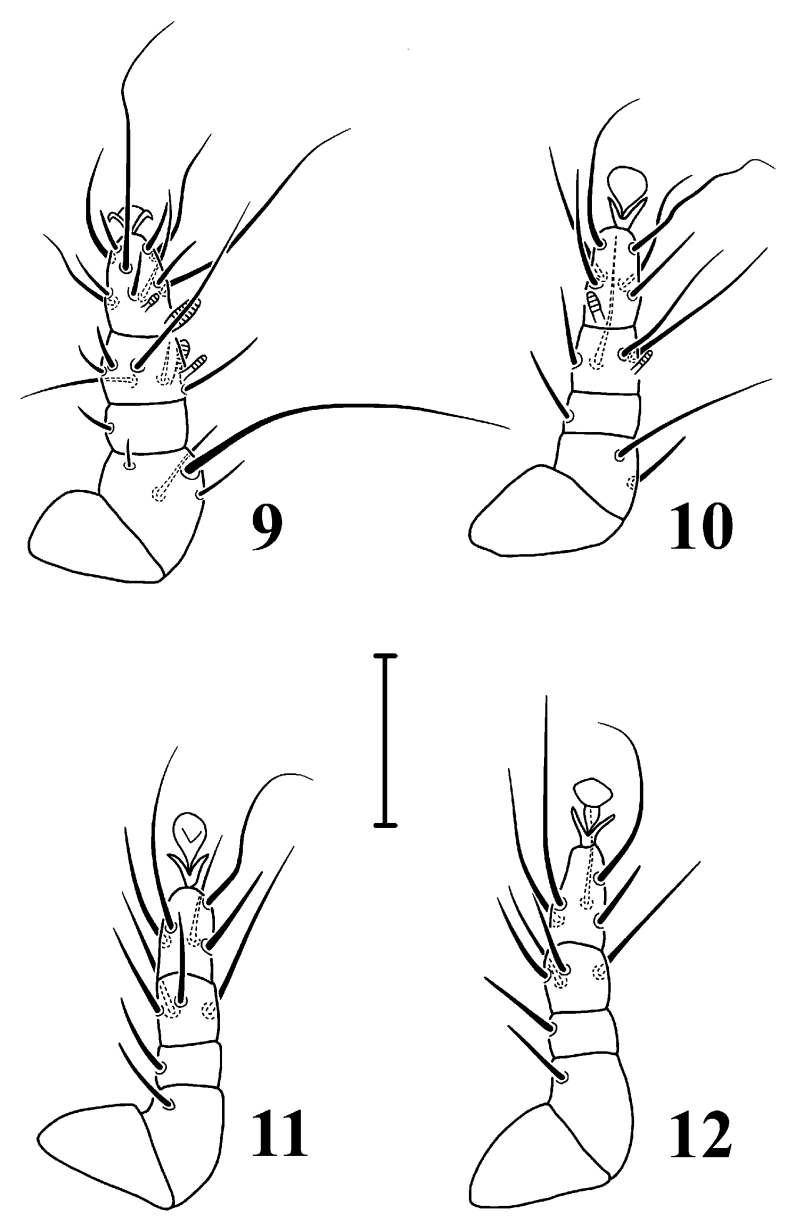

Figs 9-12. Pavania sabzevarensis sp. n., female: legs I-IV in dorsal view, respectively. Scale bar $20 \mu \mathrm{m}$.

$11(10-11)$ and 1 small porous area. Pseudanal plate with setae $p s$ 5 (5-6).

Legs (Figs 9-12). Leg I (Fig. 9): setal formula: 4-1-6(2)-11(2). Tarsus with 4 slightly blunt-ended eupathidial setae $p^{\prime}, p^{\prime \prime}, f t^{\prime}$ and $f t$ ", rest of setae on leg I slender and pointed; both $t c$ " and $p l$ " subequal in length and the longest on tarsus; solenidion $\omega_{1} 5$ (5-5) prominent, approximately spindle shaped; solenidion $\omega_{2} 3(3-4)$ finger shaped. Tibia with eupathidium $k$ stiff; solenidion $\varphi_{1} 6$ (7-8) stalked and slightly clubbed, longer than $\varphi_{2} 4$ (3-4) finger shaped. Genu with 1 seta ( $\left.v^{\prime}\right)$. Seta $d$ on femur equal in length to whole leg I; seta $v$ " longer than $l$ ',

Leg II (Fig. 10). Setal formula: 2-1-4(1)-6(1). Setae of leg attenuated and pointed except setae $l$ ' on genu and $v$ " on femur, which are needle-like, $p l$ " and $t c$ " shortest and longest setae on tarsus, respectively, solenidion $\omega 4$ (3-4) finger shaped; solenidion $\varphi 3$ (3-4) similar to $\omega$ but thinner; seta $d$ on femur 2.5 times as long as seta $v$ ".

Leg III (Fig. 11). Setal formula: 1-1-4-5. Setae of leg attenuated and pointed except setae $p l$ " on the tarsus, $v$, on genu and $d$ on femur, which are needle-like; seta $p l$ " shortest on tarsus; seta $d$ of femur as long as seta $v$ ' of genu; seta $v$ ' shorter than $v$ "' and $d$ subequal to $l$ ' on tibia.

Leg IV (Fig. 12). Setal formula: 1-1-4-5. Setae of leg attenuated and pointed except setae $p l$ ' on the tarsus, $v$ ' 

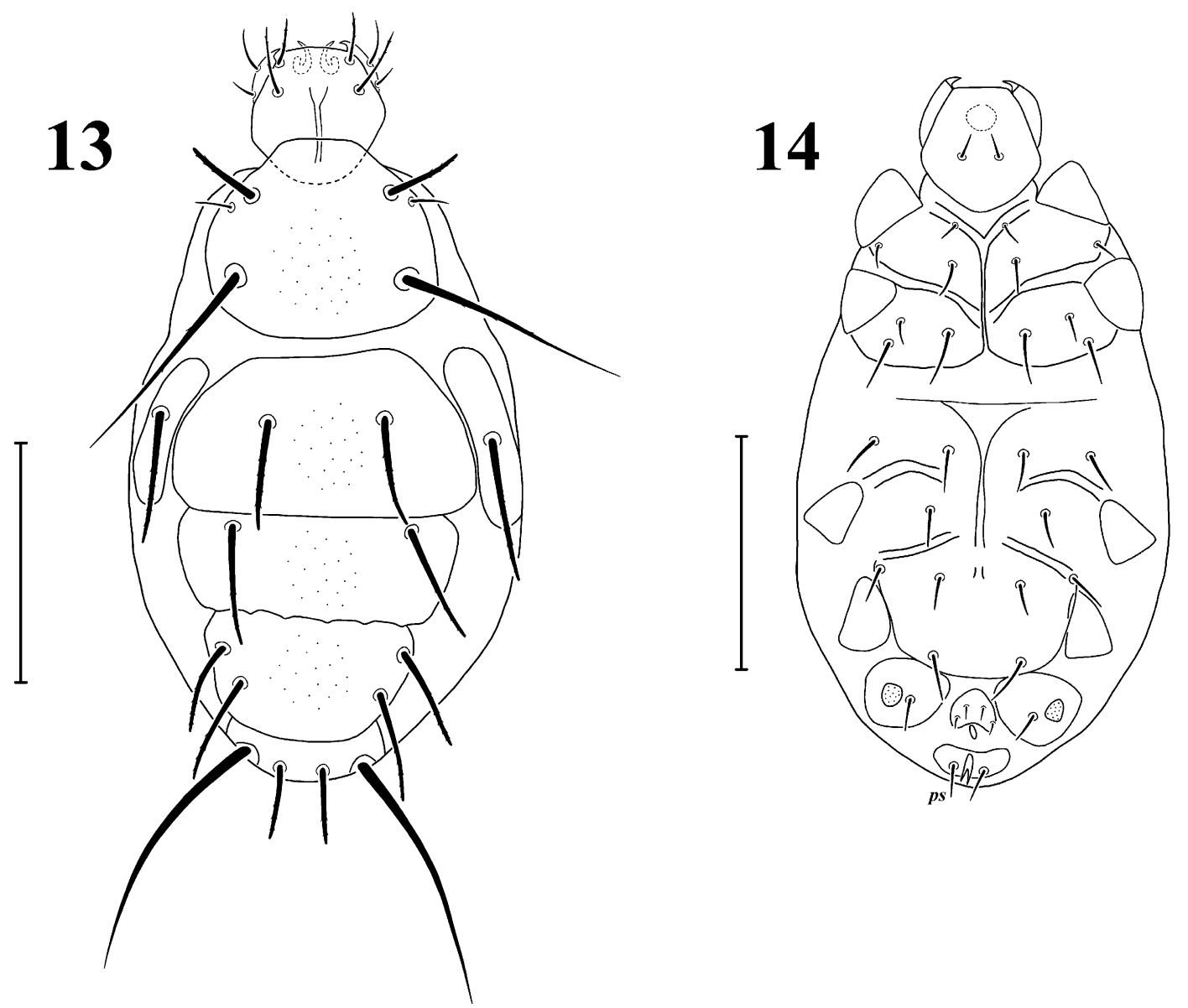

Figs 13-14. Pavania onthophagi sp. n., female. 13 - body in dorsal view; 14 - body in ventral view. Scale bars $50 \mu \mathrm{m}$.

on genu and $d$ on femur, which are needle-like; seta $v^{\prime}$ of genu slightly longer than seta $d$ on femur; on tibia setae $d$ shorter than $v$ " and slightly longer than its segment.

Male unknown.

Type material. Holotype $q$ (Sab-2-II) and $21 \%$ paratypes phoretic on Gymnopleurus mopsus persianus collected in dung pads of livestock: Northeastern Iran, Razawi Khorasan province, Mehr village in the vicinity of Sabzevar town, $36.30^{\circ} \mathrm{N}$, $57.80^{\circ} \mathrm{E}$, altitude $1,024 \mathrm{~m}$, 4.vi.2007, coll. H. Hajiqanbar.

Etymology. The specific epithet refers to the name of city Sabzevar in Northeastern Iran.

\section{Pavania onthophagi Hajiqanbar \& Khaustov sp. n.}

(Figs 13-18)

Differential diagnosis. The new species is distinguishable from two other species of this species group by the following features: cheliceral setae $c h_{1}$ approximately 1.5 times longer than $c_{2}$ (3 times in P. gymnopleuri and 1.7 times in P. sabzevarensis); dorsal idiosomal setae weakly barbed and distinctly blunt-ended, except $v_{2}, s c_{2}$ and $h_{2}$ being pointed (smooth in both other species, $c_{2}$ bluntended in $P$. gymnopleuri and $c_{2}, e$ and $f$ blunt-ended in $P$. sabzevarensis); seta $e$ almost as long as $f(e$ longer than $f$ in $P$. gymnopleuri but shorter in $P$. sabzevarensis); seta $h_{2}$ nearly 3.5 times longer than $h_{1}$ (almost 15 times in $P$. gymnopleuri and 7 times in $P$. sabzevarensis); ventral idiosomal setae smooth and needle-like, setae $2 a$ the longest in ventral aspect (the same in $P$. sabzevarensis but in $P$. gymnopleuri ventral idiosomal setae smooth, attenuated and pointed, setae $2 a$ and $2 c$ the longest in ventral aspect).

\section{Description}

Female (holotype). Length of idiosoma 136 (115-122 in 5 paratypes), width 81 (74-77).

Gnathosoma (Figs 13-14). Length of gnathosoma 28 (28-30), width 28 (26-29). Gnathosomal capsule rounded subhexagonal in dorsal aspect, as long as wide with cheliceral setae $c h_{1} 18$ (19-20) and $c h_{2} 12$ (11-13) weakly barbed. Dorsomedian apodeme evident. Cheliceral stylets 8 (7-8) curved and falcate. Subcapitulum with subcapitular setae su 5 (5-5) stiff, located on posterior half. Palpi somewhat appressed to gnathosoma (for this reason accessories of tibiotarsus not visible), exceeding apex of gnathosomal capsule, femorogenu with setae $d G e$ 9 (7-9) and $d F e$ 5 (5-6) smooth and pointed; palpcoxal setae $p p$ not visible.

Idiosomal dorsum (Fig. 13). Ovoid in shape. All dorsal shields ornamented with sparse and fairly deep dimples; in some specimens posterior margins of dorsal shields with backward pointing and equally spaced projections. Dorsal idiosomal setae weakly barbed and distinctly blunt-ended except $v_{2}, s c_{2}$ and $h_{2}$ which are pointed. Prodorsal shield subtrapezoid, its anterior margin straight and posterior margin slightly concave, with setae $v_{1} 17$ (17-18), $v_{2} 7$ (5-7), sc 50 (47-52), setae $v_{1}$ shorter 
than distance between their bases, $v_{2}$ short and located posterolaterally to $v_{1}, s c_{2}$ weakly barbed, tapered and pointed. Median shield of tergite $\mathrm{C}$ with setae $c_{1} 25$ (23-25) and each lateral shield with seta $c_{2} 30$ (28-30), $c_{1}$ approximately 0.8 times longer than $c_{2}$. Tergite $\mathrm{D}$ with setae $d 27$ (24-27) and cupuli ia situated posterior to seta $d$, seta $d$ slightly longer than $c_{1}$, posterior margin of tergite $\mathrm{D}$ usually undulated. Tergite EF with setae $e 23$ (21-23), $f 23$ (22-23) and 1 pair of cupuli im placed closer to setae $e$ on its inner posterolateral side, seta $f$ as long as $e$. Tergite $H$ with setae $h_{1} 16(15-17)$ and $h_{2} 57$ (61-62), the latter long, attenuated and pointed, seta $h_{2}$ almost 3.5 times longer than $h_{1}$. Distances between dorsal idiosomal setae: $v_{1}-v_{1} 28(27-28), v_{2}-v_{2} 38(35-36), v_{1}-v_{2}$ 4 (4-5), sc $-s c_{2} 34$ (33-35), $c_{1}-c_{1} 25$ (25-27), $d-d 36$ (36-39), e-e 35 (35-38), f-f 28 (27-29), e-f 8 (8-9), $h_{1}-h_{1} 9$ (10-10), $h_{2}-h_{2} 22$ (21-23), $h_{1}-h_{2} 6(5-6)$.

Idiosomal venter (Fig. 14). All ventral idiosomal setae smooth and needle-like. Apodemes II almost reaching to presternal apodeme; both apodemes III and IV not joined with poststernal apodeme. Coxal field I: $1 a 7(6-7), 1 b 5$ (5-5), $1 c 5(5-5), 1 c$ and $1 b$ subequal in size and shorter than 1a. Coxal field II: $2 a 12$ (11-12), $2 b 5$ (5-6), $2 c 11$ (10-11), seta $2 a 2.4$ times as long as $2 b$. Coxal field III: $3 a 9$ (8-9), $3 b 8$ (8-9), $3 c 8$ (9-9), all setae in coxal field III almost subequal in length. Coxal field IV: setae $4 a 7$ (7-9), $4 b 10$ (9-10), 4c 9 (8-9), setae $4 b$ longer than $4 a$ and $4 c$. Genital plate with setae $g_{1} 3(3-3)$ and $g_{2} 3(3-3)$. Aggenital plates each bearing 1 seta $a g$ (6-7) and 1 small porous area. Pseudanal plate with setae ps 8 (8-9) and bifurcate anal slit.

Legs (Figs 15-18). Leg I (Fig. 15): setal formula: 4-2-6(2)-11(2). Tarsus with 4 slightly blunt-ended eupathidial setae $p$ ', $p$ ", $f t^{\prime}$ and $f t$ ', rest of setae on the leg I seta-like and pointed; seta $t c$ " longest on the tarsus and longer than $p l$ "; solenidion $\omega_{1} 6(6-6)$ prominent and finger shaped; solenidion $\omega_{2} 3$ (3-3) finger shaped. Tibia with eupathidium $k$ stiff; solenidion $\varphi_{1} 7$ (6-7) stalked and fairly clubbed, longer than $\varphi_{2} 4$ (4-5) finger shaped. Genu with 2 setae ( $v^{\prime}$ and $l^{\prime}$ ). Seta $d$ on femur weakly barbed, shorter than leg I; seta $l$ " longer than $v$ ".

Leg II (Fig. 16). Setal formula: 2-1-4(1)-6(1). Setae of leg attenuated and pointed except setae $l$ ' on genu and $v$ " on femur which are needle-like; setae $v^{\prime \prime}$ on tibia, $l$ ' on genu, $d$ and $v$ "' on femur weakly barbed; seta $t c$ ' shortest on tarsus, solenidion $\omega 4$ (4-5) finger shaped; solenidion $\varphi 4$ (4-5) similar to $\omega$ but thinner; seta $d$ on femur 2.8 times as long as seta $v$ ”.

Leg III (Fig. 17). Setal formula: 1-1-4-5. Setae of leg attenuated and pointed except setae $v$ ' on genu and $d$ on femur which are needle-like; setae $l$ ' on tibia, $v$ ' on genu and $d$ on femur weakly barbed; seta $p l$ " shortest on tarsus; seta $d$ of femur shorter than seta $v$ ' of genu; setae $d$ shorter than $v$ " and $l$ ' on tibia.

Leg IV (Fig. 18). Setal formula: 1-1-4-5. Setae of leg attenuated and pointed except $v$ ' on genu and $d$ on femur which are needle-like; setae $l^{\prime}$ ' on tibia, $v^{\prime}$ on genu and $d$ on femur weakly barbed; seta $v^{\prime}$ of genu longer than seta
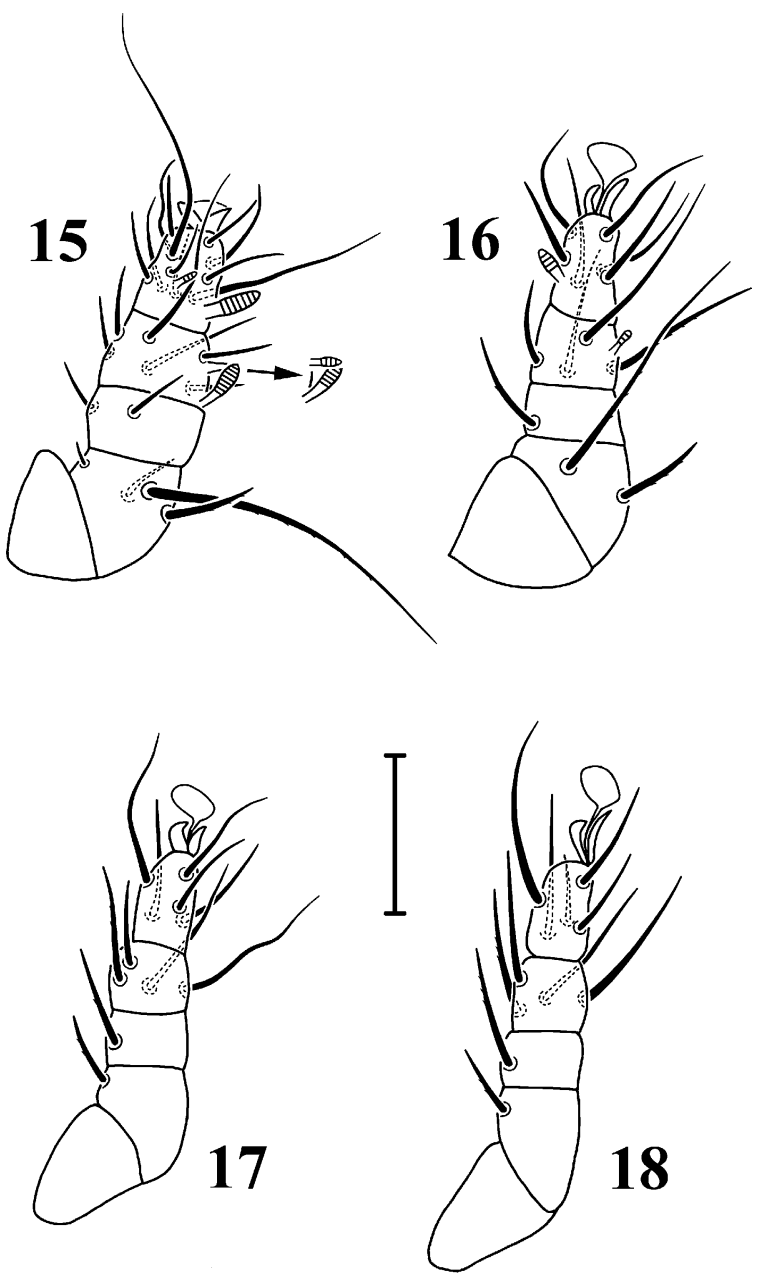

Figs 15-18. Pavania onthophagi sp. n., female: legs I-IV in dorsal view, respectively. Scale bar $20 \mu \mathrm{m}$.

$d$ of femur; on tibia setae $d$ shorter than $v$ " and longer than its segment.

Male unknown.

Type material. Holotype 9 (Bo-1) and 159 paratypes phoretic on Onthophagus (Euonthophagus) gibbosus gibbosus (Scriba, 1970) (Coleoptera: Scarabaeidae) collected in dung pads of livestock: Northeastern Iran, North Khorasan province, Esfidan village in the vicinity of Bojnord town, $37.31^{\circ} \mathrm{N}$, $57.57^{\circ} \mathrm{E}$, altitude $1,611 \mathrm{~m}, 28 . v i .2007$, coll. H. Hajiqanbar.

Additional material. 119 (Es-1), phoretic on Onthophagus (s. str.) taurus (Schreber, 1959) (Coleoptera: Scarabaeidae) collected in dung pads of livestock: Northeastern Iran, North Khorasan province, vicinity of Esfarayen town, $36.93^{\circ} \mathrm{N}, 57.74^{\circ} \mathrm{E}$, altitude 1,471 m, 26.vi.2007, coll. H. Hajiqanbar.

Etymology. The specific epithet is derived from the generic name of the host scarab beetle - Onthophagus.

\section{Pavania fusiformis species group \\ Pavania kamalii Hajiqanbar \& Khaustov sp. n.}

(Figs 19-24)

Differential diagnosis. This new species is similar to Pavania fusiformis Lombardini, 1949 but differs from it by seta $c_{1}$ longer than $c_{2} \quad\left(c_{2}\right.$ longer than $c_{1}$ in $P$. fusiformis); seta $c_{1}$ longer than $d\left(c_{1}\right.$ and $d$ subequal in $P$. 

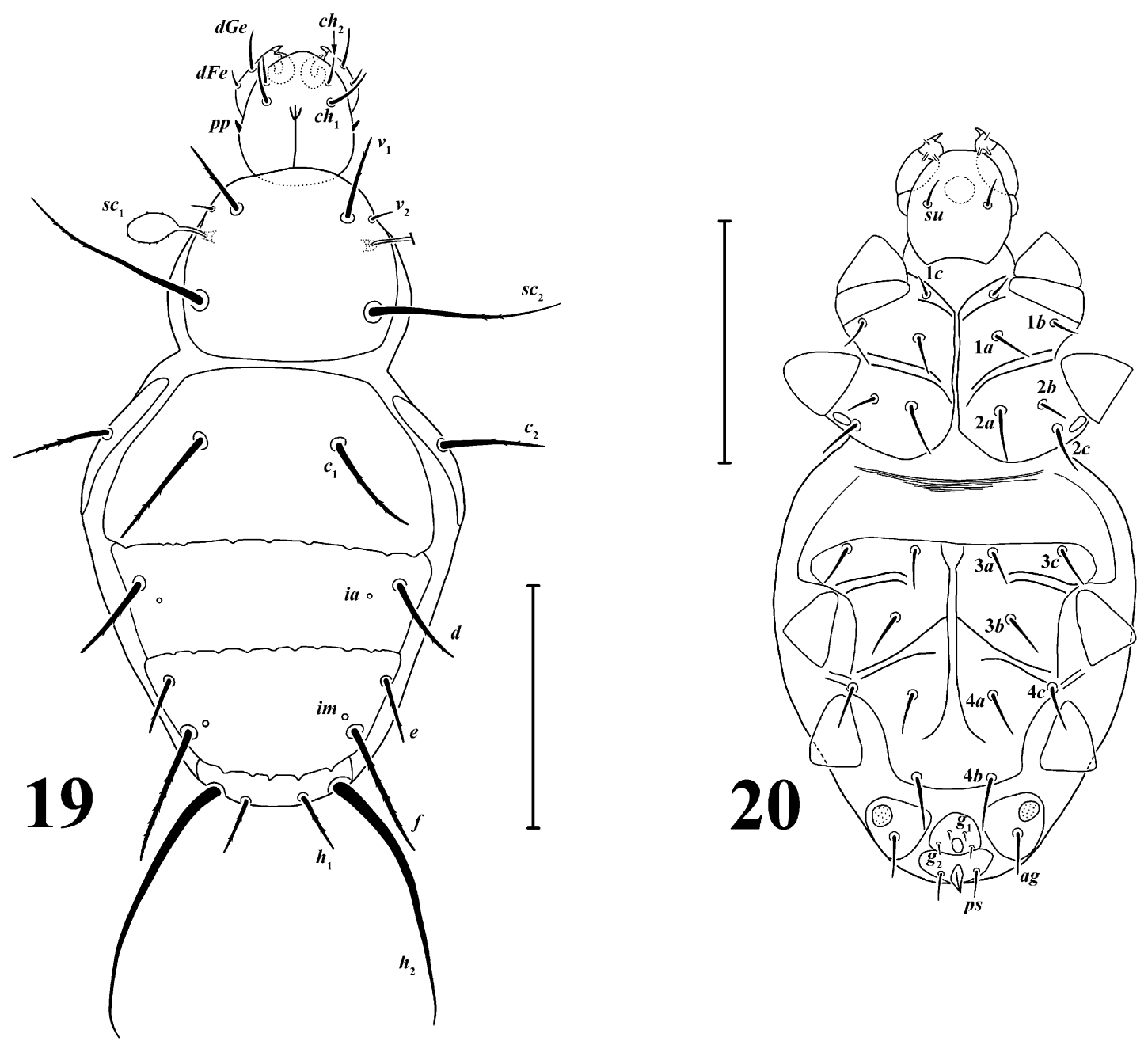

Figs 19-20. Pavania kamalii sp. n., female. 19 - body in dorsal view; 20 - body in ventral view. Scale bars $50 \mu \mathrm{m}$.

fusiformis) and seta $s c_{2}$ less than twice length of $c_{1}\left(s c_{2}\right.$ more than twice length of $c_{1}$ in $P$. fusiformis).

\section{Description}

Female (holotype). Length of idiosoma 130 (121-134 in 5 paratypes), width 78 (71-75).

Gnathosoma (Figs 19-20). Length of gnathosoma 27 (26-29), width 25 (22-25). Gnathosomal capsule rounded subquadrangular in dorsal aspect, longer than wide; dorsally with cheliceral setae $c_{1} 10$ (11-14) and ch $_{2} 6$ (7-8) smooth. Dorsomedian apodeme evident. Cheliceral stylets 9 (8-9) curved and falciform. Subcapitulum with subcapitular setae su 6 (6-7) needle-like. Pharynx rounded. Palpi conspicuous, exceeding apex of gnathosomal capsule, femurogena with 2 setae $d G e 7$ (6-7) and $d F e ~ 4$ (4-5), tibiotarsus with 2 solenidia subequal in size and 1 small seta; minute palpcoxal setae $p p$ visible and inserted near to articulation of each palp with the gnathosomal capsule.

Idiosomal dorsum (Fig. 19). Almost ovoid in shape. All dorsal shields smooth and their posterior margins with several backward pointing and more or less equally spaced projections. Dorsal idiosomal setae weakly barbed and blunt-ended except $v_{2}$ and $h_{2}$, which are smooth and pointed. Prodorsal shield subquadrangular, its anterior margin curved and posterior margin slightly concave, with setae $v_{1} 17$ (17-19), $v_{2} 4$ (4-5), $s c_{2} 39$ (39-44) and 1 pair of barbed capitate trichobothridia $s c_{1}$, setae $v_{1}$ shorter than distance between their bases, $v_{2}$ short and located laterally of $v_{1}, s c_{2}$ weakly barbed, tapered and pointed. Median shield of tergite $\mathrm{C}$ with setae $c_{1} 28$ (28-32) and each lateral shield with seta $c_{2} 22(22-25), c_{1}$ almost 1.3 times longer than $c_{2}$. Tergite D with setae $d 21$ (21-22) and cupuli ia situated posterolaterally to seta $d$, seta $c_{1}$ longer than $d$. Tergite EF with setae $e 13(13-15)$ and $f 30$ (29-31), and 1 pair of cupuli im placed closer to setae $f$ on its inner anterolateral side, seta $f 2.3$ times as long as $e$. Tergite H with setae $h_{1} 12(11-13)$ and $h_{2} 58$ (61-65), the latter long, attenuated and pointed, seta $h_{2}$ almost 4.8 times longer than $h_{1}$. Distances between dorsal idiosomal setae: $v_{1}-v_{1} 22$ (20-21), $v_{2}-v_{2} 32$ (30-32), $v_{1}-v_{2} 5$ (4-5), $s c_{2}-s c_{2} 34$ (32-34), $c_{1}-c_{1} 28$ (25-28), $d-d 52$ (50-55), e-e 44 (43-45), f-f 33 (31-33), e-f 10 (10-11), $h_{1}-h_{1} 11$ (11-12), $h_{2}-h_{2} 23(23-25), h_{1}-h_{2} 6$ (5-6).

Idiosomal venter (Fig. 20). All ventral idiosomal setae smooth and needle-like. Ventral apodemes welldeveloped; apodemes I joined with presternal apodeme; apodemes II not reaching to presternal apodeme; both apodemes III and IV not joined to poststernal apodeme. Coxal field I with setae $1 a 7(6-7), 1 b 5(5-6), 1 c 5$ (5-5), $1 c$ and $1 b$ subequal in length and shorter than $1 a$. 
Coxal field II with setae $2 a 11$ (11-13), $2 b 5$ (5-6), $2 c 10$ (11-12), seta $2 a 2.2$ times longer than $2 b$. Coxal field III with setae $3 a 8$ (9-10), $3 b 9$ (9-10), 3c 9 (10-11), all setae of coxal field III subequal in length. Coxal field IV with setae $4 a 9$ (9-10), $4 b 11$ (11-12), 4c 10 (9-10), setae $4 b$ longer than $4 a$ and $4 c$. Genital plate with setae $g_{1} 2$ (2-2), $g_{2} 3$ (3-3) short. Aggenital plates including 1 seta ag 9 (9-11) and 1 small porous area each. Pseudanal plate with setae $p s 6$ (6-7).

Legs (Fig. 21-24). Leg I almost thicker than leg II (Fig. 21): setal formula: 4-2-6(2)-11(2). Tarsus with 4 slightly blunt-ended eupathidial setae $p$ ', $p$ ”, $f t^{\prime}$ and $f t^{\prime}$, rest of setae on leg I seta-like and pointed; seta $t c$ " longest on tarsus and longer than $p l$ "; solenidion $\omega_{1} 6(5-5)$ prominent and finger shaped; solenidion $\omega_{2} 3$ (3-3) finger shaped. Tibia with eupathidium $k$ stiff; solenidion $\varphi_{1} 7$ (6-7) stalked and fairly clubbed, longer than $\varphi_{2} 3(3-4)$ finger shaped. seta $d 4$ times as long as $l$ "' on femur.

Leg II (Fig. 22). Setal formula: 2-1-4(1)-6(1). Setae of leg attenuated and pointed; seta $p l$ " shortest on tarsus, solenidion $\omega 4$ (4-4) finger shaped; solenidion $\varphi 3$ (3-3) similar to $\omega$; on femur and genu, setae $d$ and $l$ ' subequal and both longer than seta $v$ ".

Leg III (Fig. 23). Setal formula: 1-1-4-5. Setae of leg attenuated and pointed; on the tarsus seta $t c$ ' longer than its segment length; seta $d$ of femur shorter than seta $v$ ' of the genu.

Leg IV (Fig. 24). Setal formula: 1-1-4-5. Setae of leg attenuated and pointed; on tarsus seta $p l$ " shortest of all tarsals and shorter than its segment length; on tibia, seta $l$ ' longer than $d$; seta $v$ ' of genu longer than seta $d$ on the femur.

Male unknown.

Type material. Holotype $q$ (Es-3) and 119 paratypes phoretic on Scarabaeus spp. (Coleoptera: Scarabaeidae) collected in dung pads of livestock or caught by a light trap: Northeastern Iran, North Khorasan province, vicinity of Esfarayen town, $36.94^{\circ} \mathrm{N}, 57.73^{\circ} \mathrm{E}$, altitude $1,483 \mathrm{~m}, 26$. and 27.vi.2007, coll. $\mathrm{H}$. Hajiqanbar.

Etymology. The new species is named in honour of Prof. Karim Kamali, supervisor of the senior author, in recognition of his encouragement for the study of mites in Iran.

\section{Pavania elongata Hajiqanbar \& Khaustov sp. $n$.} (Figs 25-30)

Differential diagnosis. The new species differs from other species of the species group by subequal coxal setae $2 a$ and $2 c$ (28) which are more than twice as long as $2 b$ (13); seta $c_{1}$ shorter than $c_{2}$ but longer than $d$; seta $f$ nearly 1.2 times as long as $e$. This species is also characterized by having an elongate idiosoma (mites of the genus Pavania usually have fusiform idiosoma).

\section{Description}

Female (holotype). Length and width of idiosoma 200 and 85 , respectively.

Gnathosoma (Fig. 25-26). Length of gnathosoma 28 and 23, respectively. Gnathosomal capsule rounded subquadrangular in dorsal aspect, longer than wide; cheliceral setae $c h_{1} 21$ and $c h_{2} 10$ smooth. Dorsomedian apo-
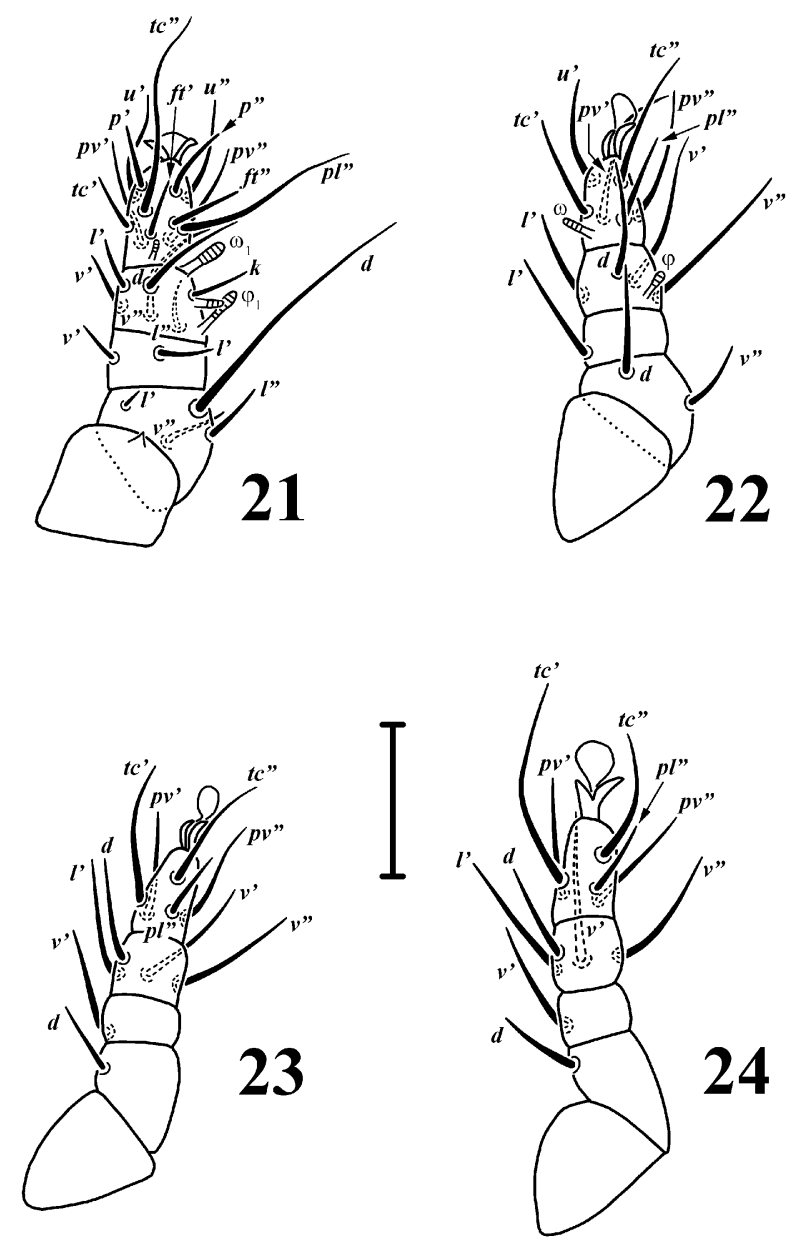

Figs 21-24. Pavania kamalii sp. n., female: legs I-IV in dorsal view, respectively. Scale bar $20 \mu \mathrm{m}$.

deme evident. Cheliceral stylets curved and falciform, 6 long. Subcapitulum with subcapitular setae su 17 located on posterior half. Pharynx rounded. Palpi conspicuous, exceeding apex of gnathosomal capsule, femurogenu with setae $d G e 11$ and $d F e$ 10, tibiotarsus with 2 solenidia, one longer than the other, and 1 small seta; minute palpcoxal setae $p p$ inserted near to articulation of each palp with gnathosomal capsule.

Idiosomal dorsum (Fig. 25). Cylindrical in shape. All dorsal shields smooth and their posterior margins without small projections. Dorsal idiosomal setae weakly barbed, attenuated and pointed except $h_{2}$ which is smooth. Prodorsal shield subquadrangular, its anterior margin slightly curved and posterior margin concave, with setae $v_{1} 28, v_{2}$ $9, s c_{2} 59$ and 1 pair of smooth capitate trichobothridia $s c_{1}$, setae $v_{1}$ longer than distance between their bases, $v_{2}$ short and located posterolaterally of $v_{1}$. Median shield of tergite $\mathrm{C}$ with setae $c_{1} 26$ and each lateral shield with seta $c_{2} 36$ [one of the lateral shields is drawn from below due to rotation of the specimen during slide preparation], $c_{2}$ almost 1.4 times longer than $c_{1}$. Tergite $\mathrm{D}$ with setae $d 23$ and cupuli ia situated posterolaterally to seta $d$, seta $c_{2}$ longer than $d$. Tergite EF with setae $e 20$ and $f 23$, and 1 pair of cupuli im placed close to setae $f$ on its inner anterolateral side, seta $f$ approximately 1.2 times as long as $e$. 


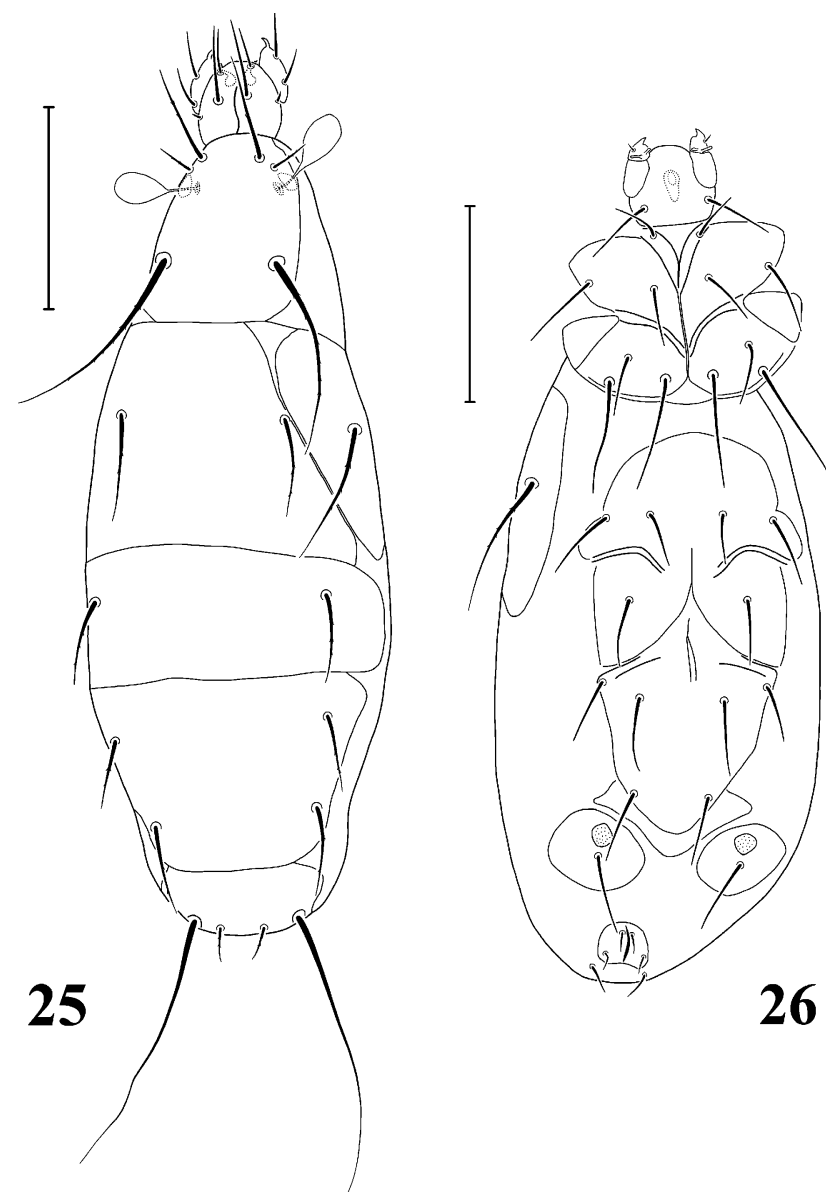

Figs 25-26. Pavania elongata sp. n., female. 25 - body in dorsal view; 26 - body in ventral view. Scale bars $50 \mu \mathrm{m}$.

Tergite H with setae $h_{1} 9$ and $h_{2} 67$ long, seta $h_{2}$ almost 7.4 times longer than $h_{1}$. Distances between dorsal idiosomal setae: $v_{1}-v_{1} 14, v_{2}-v_{2} 21, v_{1}-v_{2} 4, s c_{2}-s c_{2} 28, c_{1}-c_{1}$ 40, $d-d$ 55, e-e 52, $f-f$ 38, e-f 23, $h_{1}-h_{1} 11, h_{2}-h_{2} 27$, $h_{1}-h_{2} 7$.

Idiosomal venter (Fig. 26). All ventral idiosomal setae smooth, tapered and pointed. Apodemes I joined to thin presternal apodeme; apodemes II reaching presternal apodeme; both apodemes III and IV not joined to poststernal apodeme. Coxal field I: $1 a 14,1 b 16,1 c 12,1 b$ longer than $1 c$ and $1 a$. Coxal field II: $2 a 28,2 b 13,2 c 28$, setae $2 a$ and $2 c$ equal in length and the longest on ventral side. Coxal field III: $3 a 13,3 b 17,3 c 17$, setae $3 b$ and $3 c$ equal in length and longer than $3 a$. Coxal field IV: setae $4 a 18$, $4 b 18,4 c 16$, setae $4 a$ and $4 b$ subequal in length and longer than $4 c$. Genital plate with subequal short setae $g_{1}$ 5, $g_{2}$ 5. Aggenital plates including 1 seta $a g 19$ and 1 small porous area each. Pseudanal plate with setae $p s 9$.

Legs (Figs 27-30). Leg I thicker and longer than other legs (Fig. 27): setal formula: 4-2-6(2)-11(2). Tarsus with 4 slightly blunt-ended eupathidial setae $p$ ', $p$ ", $f t$ ' and $f t$ ', rest of setae on leg I slender and pointed; seta $p l$ " longest on tarsus and longer than $t c$ "; solenidion $\omega_{1} 5$ prominent, slightly stalked and finger shaped; solenidion $\omega_{2} 4$, finger shaped. Tibia with eupathidium $k$; solenidion $\varphi_{1} 6$ stalked and distinctly clubbed, longer than $\varphi_{2} 4$ finger shaped.
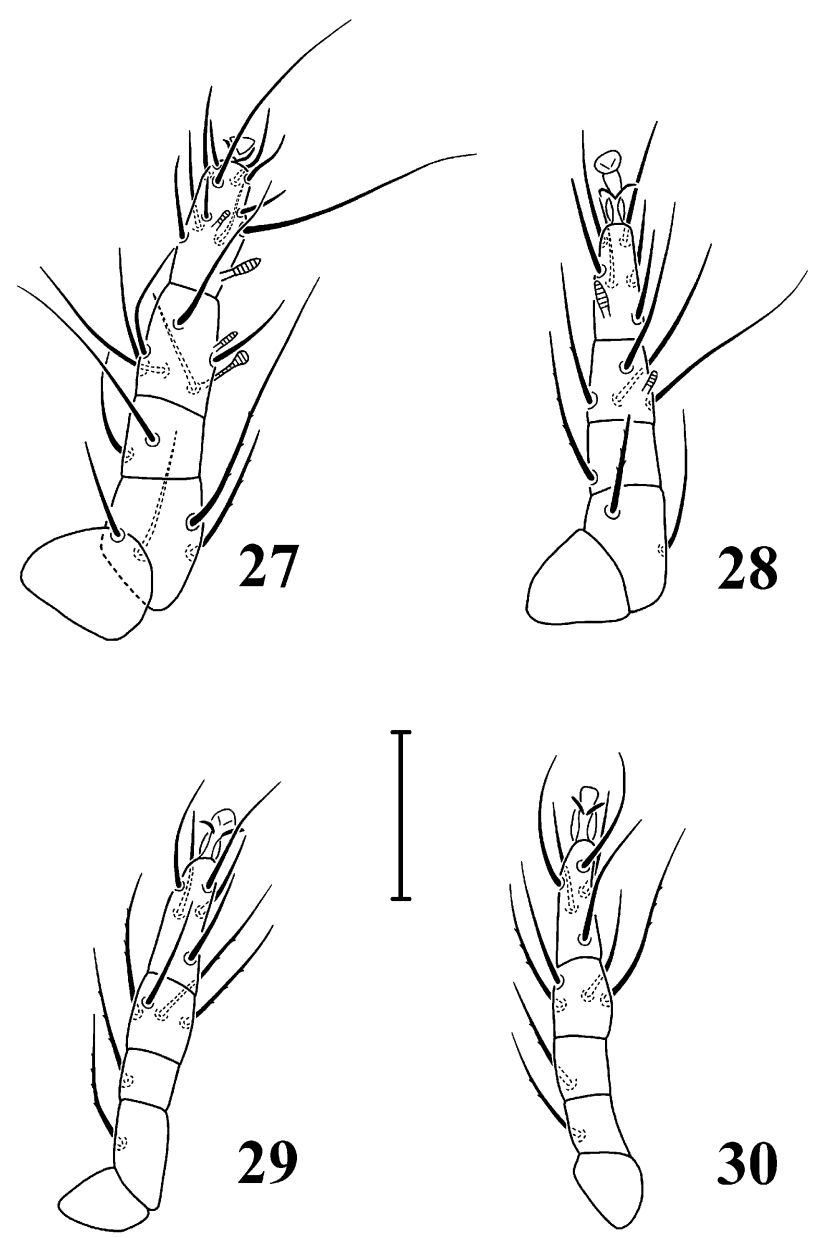

Figs 27-30. Pavania elongata sp. n., female: legs I-IV in dorsal view, respectively. Scale bar $20 \mu \mathrm{m}$.

Seta $d 2$ times as long as l" on femur; both $d$ and $l$ " weakly barbed.

Leg II (Fig. 28). Setal formula: 2-1-4(1)-6(1). Setae of leg attenuated and pointed except $d$ on femur which is blunt-ended; setae $l$ ' on tibia and genu and seta $d$ on femur weakly barbed; setae $p v$ " and $p l$ " subequal in length and both the shortest setae on tarsus, solenidion $\omega$ 4 finger shaped and fairly stalked; solenidion $\varphi 3$ finger shaped; on femur seta $v$ " longer than $d$.

Leg III (Fig. 29). Setal formula: 1-1-4-5. Setae of leg attenuated and pointed; setae $l^{\prime}, v^{\prime}$ and $v^{\prime \prime}$ on tibia, $v^{\prime}$ on genu and $d$ on femur weakly barbed; seta $t c$ ' on tarsus shorter than its segment length; seta $d$ of femur almost as long as seta $v^{\prime}$ of genu.

Leg IV (Fig. 30). Setal formula: 1-1-4-5. Setae on leg attenuated and pointed; setae $l$ ' and $v$ "' on tibia, $v^{\prime}$ on the genu and $d$ on femur weakly barbed; seta $p l$ " on tarsus longer than its segment length; seta $l$ ' on tibia approximately as long as $d$; seta $v$ ' of genu and seta $d$ of femur subequal in length.

\section{Male unknown.}

Type material. Holotype $q$ (Ms-6) phoretic on an unidentified carabid beetle (Coleoptera: Carabidae) collected on surface of the ground: Northeastern Iran, North Khorasan province, Haver village, elevations of Maneh and Samalghan town, 


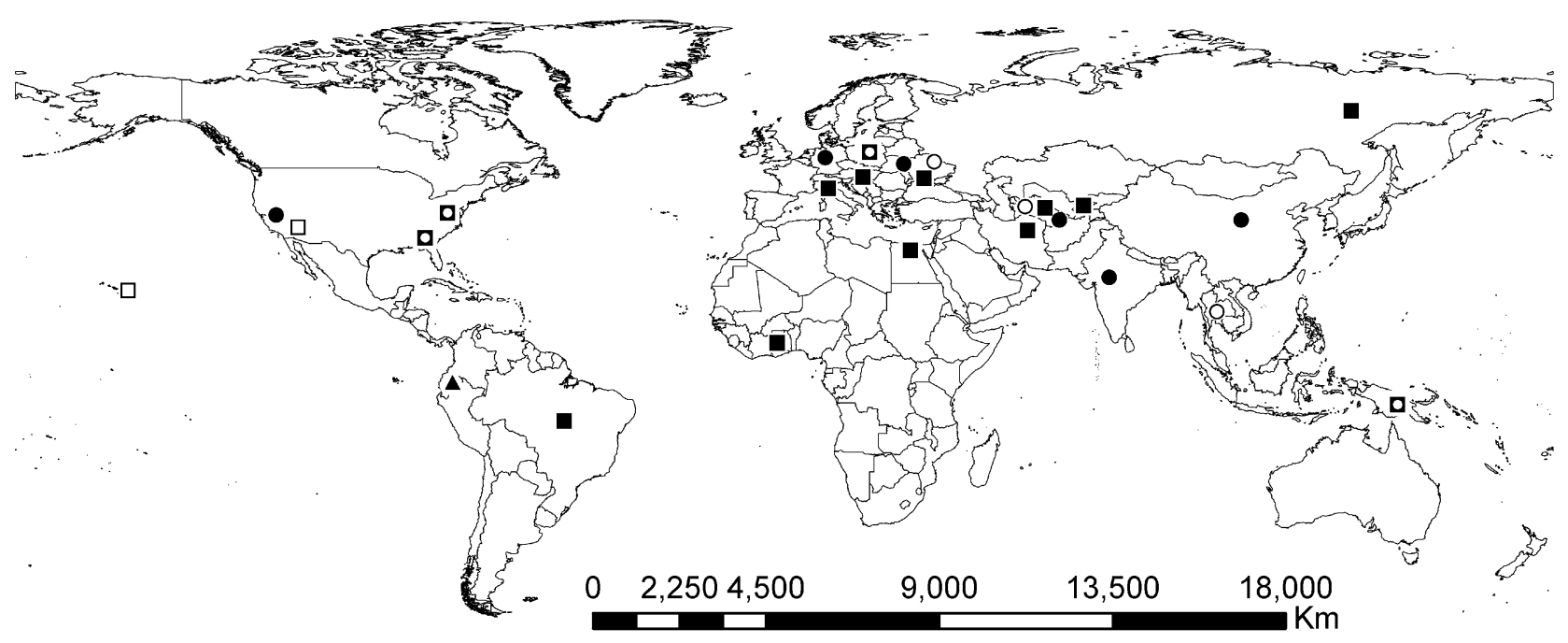

Fig. 31. Distribution of the dolichocybid genera in the world.

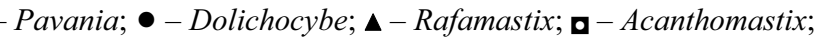
$\square$-Dolichomotes; O-Formicomotes.

$37.7^{\circ} \mathrm{N}, 56.4^{\circ} \mathrm{E}$, altitude $2,365 \mathrm{~m}, 30 . v i .2006$, coll. H. Hajiqanbar.

Etymology. The specific epithet is derived from the Latin root of "elongatus" meaning prolonged, which refers to the elongate idiosoma of this species.

\section{DISCUSSION}

Sevastianov (1980) classified five genera of the family Dolichocybidae in the two subfamilies Formicomotinae and Dolichocybinae, based on the presence or absence of trichobothridia and numbers of setae on the coxal fields. He considered absence of trichobothridia and presence of one pair of setae on each coxal field as features defining the subfamily Formicomotinae, which included the genera Dolichomotes Smiley, 1967, Acanthomastix Mahunka, 1970 and Formicomotes Sevastianov, 1980. He placed the genera Pavania Lombardini, 1947 and Dolichocybe Krantz, 1957 in the subfamily Dolichocybinae, characterized by the presence of the trichobothridia and more than one and up to four pairs of setae on the coxal fields.

Later on, Magowski (1997) described the genus Rafamastix and placed it in the subfamily Formicomotinae. In mites of this genus, however, coxal fields III and IV each bear two pairs of setae.

The gymnopleuri species group of genus Pavania described above is morphologically and ecologically very similar to the fusiformis group. Even the leg setation in these two groups is identical (Figs 3-6 and 21-24). Likewise, we recorded species of the gymnopleuri group phoretic on scarab beetles, which are also recorded as hosts of the fusiformis species group. The new species group differs from the fusiformis group by a single probably apomorphic feature - loss of trichobothridia. The fusiformis group is not defined by a distinct apomorphy and may be a paraphyletic stem group. Thus, the genus Pavania belongs obviously to the subfamily Dolichocybinae regardless of the lack of trichobothridia (being one of Sevastianov's criteria for diagnosis of the subfamily Formicomotinae) in the newly defined gymnopleuri group.
Features of the recently discovered taxa (after 1980) suggest that the previously defined characters of these subfamilies are not convenient and constant. On the one hand, Rafamastix contravenes the number of setae on coxal fields III and IV in the subfamily Formicomotinae, and on the other, the new Pavania gymnopleuri species group invalidates the presence of trichobothridia as a constant character of the subfamily Dolichocybinae. Therefore, additional characters are needed to define the subfamilies. Leg setation of all genera of the family Dolichocybidae were studied (see Table 1). This revealed some useful characters that were ignored in the past owing to the often imperfect description of leg setation at the generic level.

It should be noted that the solenidia in genera Dolichomotes and Formicomotes are attached in a somewhat unusual way. All solenidia in these genera are inserted into the surface of the leg segments, except $\varphi_{1}$ on first tibia, which has a normal structure, emergent and stalked. In this regard, Dolichomotes crossi is an exception in that solenidion $\omega_{2}$ is not pustulate but rather emergent and stick-like.

According to the summarized data in Table 1, some additional features (putative apomorphies), originating from leg setation, can be proposed for improving the diagnoses of the two subfamilies.

Dolichocybinae: solenidion $\varphi$ on tibia III absent (i), solenidion $\varphi$ on tibia IV absent (ii).

Formicomotinae: setae $v^{\prime \prime}$ and $l$ ' on femur I absent (i), seta $v^{\prime}$ on genu I absent (ii), setae $u$ ' and $u$ ', on tarsus I absent (iii), seta $u^{\prime}$ on tarsus II absent (iv), seta tc' on tarsus IV absent (v).

The family now includes six genera and 35 species. The genus Pavania, including the five new species described, includes 18 species and constitutes the largest genus of the family. The remaining 17 species are distributed as follows: Dolichocybe (8 species), Acanthomastix (4), Dolichomotes (2), Formicomotes (2) and Rafamastix (1). 
TABLE 1. Leg setation of the family Dolichocybidae (females).

\begin{tabular}{|c|c|c|c|c|c|c|}
\hline & 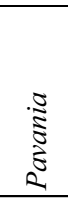 & 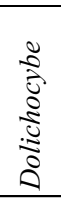 & 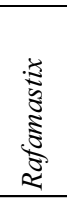 & 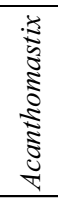 & 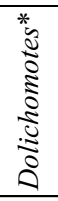 & 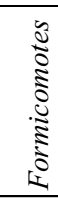 \\
\hline \multicolumn{7}{|l|}{ Leg I } \\
\hline Femur & $\begin{array}{c}d \\
l^{\prime}, \\
v^{\prime}, \\
l,\end{array}$ & $\begin{array}{l}d \\
l, \\
v^{\prime}, \\
l,\end{array}$ & $\begin{array}{l}d \\
l^{\prime \prime} \\
- \\
-\end{array}$ & $\begin{array}{l}- \\
l^{\prime}, \\
- \\
-\end{array}$ & $\begin{array}{l}- \\
l^{\prime \prime} \\
- \\
-\end{array}$ & $\begin{array}{l}- \\
l, \\
- \\
-\end{array}$ \\
\hline Genu & $\begin{array}{c}v^{\prime} \\
l^{* * *}\end{array}$ & $\begin{array}{l}v^{\prime} \\
l^{\prime}\end{array}$ & $\bar{l}$ & $\bar{l}$ & $\bar{l}$ & $\bar{l}$ \\
\hline Tibia & $\begin{array}{c}\varphi_{1} \\
\varphi_{2} \\
k \\
d \\
d, \\
l^{\prime}, \\
v^{\prime} \\
v^{\prime} \\
l^{\prime}\end{array}$ & $\begin{array}{c}\varphi_{1} \\
\varphi_{2} \\
k \\
d \\
l^{\prime \prime} \\
v^{\prime}, \\
v^{\prime} \\
l,\end{array}$ & $\begin{array}{c}\varphi_{1} \\
\varphi_{2} \\
k \\
d \\
l^{\prime}, \\
v^{\prime}, \\
v^{\prime} \\
l,\end{array}$ & $\begin{array}{c}\varphi_{1} \\
\varphi_{2} \\
k \\
d \\
l, \\
v^{\prime}, \\
- \\
l\end{array}$ & $\begin{array}{c}\varphi_{1} \\
\varphi_{2} \\
k \\
d \\
l^{\prime \prime} \\
v^{\prime}, \\
- \\
\bar{l},\end{array}$ & $\begin{array}{c}\varphi_{1} \\
\varphi_{2} \\
k \\
d \\
l^{\prime}, \\
v^{\prime}, \\
- \\
l\end{array}$ \\
\hline Tarsus & $\begin{array}{c}\omega_{1} \\
\omega_{2} \\
p^{\prime} \\
p^{\prime}, \\
t c c^{\prime}, \\
t c c^{\prime} \\
f t^{\prime} \\
f t^{\prime}, \\
p v^{\prime} \\
p v^{\prime}, \\
p l^{\prime}, \\
u, \\
u^{\prime},\end{array}$ & $\begin{array}{c}\omega_{1} \\
\omega_{2} \\
p^{\prime} \\
p^{\prime}, \\
t c c^{\prime} \\
t c^{\prime}, \\
f t^{\prime} \\
f t^{\prime}, \\
p v^{\prime} \\
p v^{\prime}, \\
- \\
u^{\prime} \\
u^{\prime},\end{array}$ & $\begin{array}{c}\omega_{1} \\
\omega_{2} \\
- \\
- \\
t c \\
t c, \\
f c^{\prime}, \\
f t, \\
p v^{\prime} \\
p v^{\prime}, \\
- \\
- \\
-\end{array}$ & $\begin{array}{c}\omega_{1} \\
\omega_{2} \\
p, \\
- \\
t c, \\
t c{ }^{\prime}, \\
f t^{\prime} \\
f t, \\
p v^{\prime} \\
p v^{\prime}, \\
p l, \\
- \\
- \\
\end{array}$ & $\begin{array}{c}\omega_{1} \\
\omega_{2} \\
p^{\prime} \\
- \\
t c \\
t c, \\
- \\
- \\
p v^{\prime} \\
p v^{\prime}, \\
p l, \\
- \\
- \\
\end{array}$ & $\begin{array}{c}\omega_{1} \\
\omega_{2} \\
p^{\prime} \\
p, \\
t c \\
t c, \\
-, \\
- \\
- \\
p v^{\prime} \\
p v^{\prime}, \\
p l, \\
- \\
-\end{array}$ \\
\hline \multicolumn{7}{|l|}{ Leg II } \\
\hline Femur & $\begin{array}{c}d \\
v^{\prime \prime}\end{array}$ & $\begin{array}{c}d \\
v^{\prime \prime}\end{array}$ & $\begin{array}{c}d \\
l, "\end{array}$ & $\bar{l}$, & $\bar{l}$, & $\bar{l}$, \\
\hline Genu & $l^{\prime}$ & $l^{\prime}$ & $l^{\prime}$ & $l^{\prime}$ & $l^{\prime}$ & $l^{\prime}$ \\
\hline Tibia & $\begin{array}{c}\varphi \\
d \\
v^{\prime}, \\
v^{\prime} \\
l^{\prime}\end{array}$ & $\begin{array}{c}\varphi \\
d \\
v^{\prime}, \\
v^{\prime} \\
l\end{array}$ & $\begin{array}{c}\varphi \\
d \\
v^{\prime}, \\
v^{\prime} \\
l^{\prime}\end{array}$ & $\begin{array}{c}\varphi \\
d \\
v^{\prime} \\
- \\
l^{\prime}\end{array}$ & $\begin{array}{c}\varphi \\
d \\
v^{\prime} \\
- \\
l^{\prime}\end{array}$ & $\begin{array}{c}\varphi \\
d \\
v " \\
- \\
l\end{array}$ \\
\hline Tarsus & $\begin{array}{c}\omega \\
t c \\
t c, \\
p v^{\prime}, \\
p v, \\
p l, \\
u^{\prime},\end{array}$ & $\begin{array}{c}\omega \\
t c \\
t c, \\
p v \\
p v, \\
p v, \\
p l, \\
u^{\prime},\end{array}$ & $\begin{array}{c}\omega \\
t c \\
t c, \\
p v^{\prime} \\
p v^{\prime}, \\
p l^{\prime}, \\
-\end{array}$ & $\begin{array}{c}\omega \\
t c \\
t c, \\
p v^{\prime} \\
p v, \\
p l, \\
-\end{array}$ & $\begin{array}{c}\omega \\
t c \\
t c, \\
p v^{\prime} \\
p v, \\
p l, \\
-\end{array}$ & $\begin{array}{c}\omega \\
t c \\
t c, \\
p v \\
p v \\
p v, \\
p l, \\
-\end{array}$ \\
\hline \multicolumn{7}{|l|}{ Leg III } \\
\hline $\begin{array}{l}\text { Femur } \\
\text { Genu } \\
\end{array}$ & $\begin{array}{l}d \\
v^{\prime}\end{array}$ & $\begin{array}{l}d \\
v^{\prime}\end{array}$ & $\frac{l^{\prime}(?)}{l^{\prime}}$ & $l^{\prime \prime}$ & $l^{\prime}$ & $l^{\prime}$ \\
\hline Tibia & $\begin{array}{l}- \\
d \\
v^{\prime}, \\
v^{\prime} \\
l^{\prime}\end{array}$ & $\begin{array}{l}- \\
d \\
v^{\prime}, \\
v^{\prime} \\
l^{\prime}\end{array}$ & $\begin{array}{c}\varphi \\
d \\
v^{\prime}, \\
v^{\prime} \\
l\end{array}$ & $\begin{array}{c}\varphi \\
d \\
v " \\
- \\
l\end{array}$ & $\begin{array}{c}\varphi \\
d \\
v \\
- \\
l^{\prime}\end{array}$ & $\begin{array}{c}\varphi \\
d \\
v^{\prime} \\
- \\
l\end{array}$ \\
\hline Tarsus & $\begin{array}{l}t c^{\prime} \\
t c, \\
p v^{\prime} \\
p v^{\prime}, \\
p l^{\prime \prime}\end{array}$ & $\begin{array}{l}t c^{\prime} \\
t c " \\
p v^{\prime} \\
p v^{\prime}, \\
p l^{\prime \prime}\end{array}$ & $\begin{array}{l}t c^{\prime} \\
t c " \\
p v^{\prime} \\
p v^{\prime}, \\
p l^{\prime}\end{array}$ & $\begin{array}{l}t c^{\prime} \\
t c, \\
p v^{\prime} \\
p v, \\
p l^{\prime},\end{array}$ & $\begin{array}{l}- \\
t c, \\
p v \\
p v, \\
p v^{\prime}, \\
\end{array}$ & $\begin{array}{l}t c \\
t c, \\
p v \\
p v^{\prime}, \\
p l \\
p l\end{array}$ \\
\hline \multicolumn{7}{|l|}{ Leg IV } \\
\hline $\begin{array}{l}\text { Femur } \\
\text { Genu }\end{array}$ & $\frac{d}{v^{\prime}}$ & $\frac{d}{v^{\prime}}$ & $\frac{l^{\prime}(?)}{l^{\prime}}$ & $\frac{l^{\prime \prime}}{l^{\prime}}$ & $\frac{-}{l}$ & - \\
\hline Tibia & $\begin{array}{c}- \\
d \\
v^{\prime}, \\
v^{\prime} \\
l^{\prime}\end{array}$ & $\begin{array}{l}- \\
d \\
v^{\prime}, \\
v^{\prime} \\
l^{\prime}\end{array}$ & $\begin{array}{c}\varphi \\
d \\
v^{\prime}, \\
v^{\prime} \\
l\end{array}$ & $\begin{array}{c}\varphi \\
d \\
v^{\prime}, \\
- \\
l^{\prime}\end{array}$ & $\begin{array}{c}\varphi \\
d, \\
v^{\prime \prime} \\
- \\
l,\end{array}$ & $\begin{array}{c}\varphi \\
d \\
v^{\prime}, \\
- \\
l\end{array}$ \\
\hline Tarsus & $\begin{array}{l}t c^{\prime} \\
t c, \\
p v^{\prime} \\
p v, \\
p l^{\prime},\end{array}$ & $\begin{array}{l}t c \\
t c, \\
p v \\
p v^{\prime}, \\
p v^{\prime},\end{array}$ & $\begin{array}{l}- \\
t c ", \\
p v \\
p v^{\prime}, \\
p l\end{array}$ & $\begin{array}{l}- \\
t c ", \\
p v^{\prime} \\
p v, \\
p l\end{array}$ & $\begin{array}{l}- \\
t c ", \\
p v, \\
p v, \\
p l,\end{array}$ & $\begin{array}{c}- \\
t c \\
p v \\
p v \\
p v, \\
p l\end{array}$ \\
\hline
\end{tabular}

* based on D. crossi; ** lacking in P. sabzevarensis sp. n.
The newly described taxa expanded the geographical distribution of the dolichocybid mites in the Palaearctic Region. Fig. 31 shows map of the distribution of the genera of the family. All six zoogeographic realms harbour at least one dolichocybid genus. There is only one genus in each of the Afrotropical and Australasian realms, Pavania and Acanthomastix, respectively. There are two genera in the Neotropical realm, Pavania and Rafamastix, the latter being restricted to that realm. There are three genera in both the Oriental and Nearctic realms; Dolichocybe, Dolichomotes and Formicomotes in the Oriental, Formicomotes is replaced by Acanthomastix in the Nearctic. Finally, four genera and most of the dolichocybid mites occur in the Palaearctic realm.

\section{Key to world genera of the family Dolichocybidae (females)}

1 Each coxal field with 3 pairs of setae; solenidion on tibiae III-IV absent (subfamily Dolichocybinae). ......... 2

- Each coxal field with less than 3 pairs of setae; solenidion on tibiae III-IV present (subfamily Formicomotinae).... . 3

2 Gnathosoma longer than wide; chelicerae small and indistinct; tarsus I with 10 setae ( $p l$ " absent); with deep constriction between propodosoma and hysterosoma which are separated by soft and transversely striated cuticle......... .......................... Dolichocybe Gnathosoma hardly as long as wide; chelicerae large and distinct; tarsus I with 11 setae ( $p l$ " present); without deep constriction between propodosoma and hysterosoma....... ............................. Pavania

3 Coxal fields III-IV with 2 pairs of setae each... Rafamastix Coxal fields III-IV with 1 pair of setae each. ......... 4

4 All solenidia emergent; femora III-IV each with one seta $\left(l\right.$ '); tarsus I with both fastigial setae $\left(f t\right.$ ', $\left.f t^{\prime \prime}\right) \ldots \ldots \ldots \ldots$.

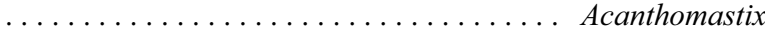
Most solenidia joined to surface of leg and pustulate; femora III-IV without seta; tarsus I without fastigial setae. . . . . . 5 5 Tarsus III with 4 setae ( $t c^{\prime}$ absent); tarsus I with 6 setae ( $p$ " absent)....................... Dolichomotes Tarsus III with 5 setae ( $t c$ ' present); tarsus I with 7 setae ( $p$ " present $) \ldots \ldots \ldots \ldots \ldots \ldots \ldots \ldots$ Formicomotes

\section{Key to world species of the genus Pavania (females)}

1 Trichobothridia absent (gymnopleuri species group)..... 2 Trichobothridia present (fusiformis species group). . . . . 4 4

2 Setae $v_{1}$ longer than distance between their bases; setae $c h_{1} 3$ times longer than $c h_{2}$; setae $e$ longer than $f$; setae $h_{2} 15$ times

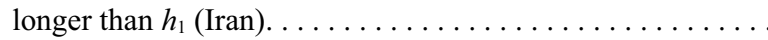
.......... P. gymnopleuri Hajiqanbar \& Khaustov sp. n.

- Setae $v_{1}$ shorter than distance between their bases; setae $c h_{1}$ less than 3 times longer than $c h_{2}$; setae $e$ never longer than $f$; setae $h_{2}$ at most 7 times longer than $h_{1} \ldots \ldots \ldots \ldots \ldots$

3 Genu I with one seta $\left(v^{\prime}\right)$; dorsal idiosomal setae smooth; setae $c_{1}$ longer than $c_{2}$; setae $c_{1}$ and $d$ pointed (Iran)....... ......... P. sabzevarensis Hajiqanbar \& Khaustov sp. n. Genu I with two setae $\left(v^{\prime}, l^{\prime}\right)$; dorsal idiosomal setae weakly barbed; setae $c_{2}$ longer than $c_{1}$; setae $c_{1}$ and $d$ distinctly blunt-ended (Iran). . . . . . . . . . . . . . . . . . .......... P. onthophagi Hajiqanbar \& Khaustov sp. n.

4 Setae $h_{2}$ less than 3.5 times longer than $h_{1} \ldots \ldots \ldots \ldots 5$ Setae $h_{2}$ more than 3.5 times longer than $h_{1} \ldots \ldots \ldots 12$

5 Setae $c_{1}$ reaching beyond bases of setae $f$; setae $c_{1}$ longer than $h_{2}$; setae $d$ and $h_{2}$ subequal (Ghana) . . . . . . . . .................. P. perhirsuta Mahunka, 1973 
- Setae $c_{1}$ never reaching beyond bases of setae $f$; setae $c_{1}$ shorter than $h_{2}$; setae $d$ shorter than $h_{2} \ldots \ldots \ldots \ldots \ldots 6$

6 Setae $h_{1}$ longer than or subequal to $d$, e and $f \ldots \ldots \ldots 7$

- Setae $h_{1}$ shorter than $d, e$ and $f \ldots \ldots \ldots \ldots \ldots \ldots 11$

7 Setae $h_{1}$ longer than $s c_{2}$; setae $s c_{2}$ distinctly shorter than distance between their bases; seta $e$ inserted at the same level as seta $f$ (Ghana).......... P. equisetosa Mahunka, 1975

- Setae $h_{1}$ shorter than $s c_{2}$; setae $s c_{2}$ longer than or subequal to distance between their bases; seta $f$ inserted posteriorly to

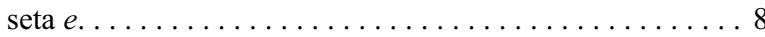

8 Setae $s c_{2}$ distinctly longer than distance between their bases; setae $s c_{2}$ reaching beyond bases of setae $c_{1} \ldots \ldots \ldots 9$

- Setae $s c_{2}$ subequal to distance between their bases; setae $s c_{2}$ never reaching beyond bases of setae $c_{1} \ldots \ldots \ldots \ldots 10$

9 Setae $c_{1}$ longer than $c_{2}$; setae $h_{1}$ longer than $e$; setae $h_{1}$ and $v_{1}$ subequal (Ukraine, Slovakia). . P. riparia Sevastianov, 1980

- Setae $c_{2}$ longer than $c_{1}$; setae $h_{1}$ and $e$ subequal; setae $h_{1}$ longer than $v_{1}$ (Ghana).......... P. luisiae Mahunka, 1974

10 Setae $c_{1}, d$, e and $f$ blunt-ended; setae $v_{1}$ reaching beyond bases of setae $c h_{1}$ (Russia). . . . . . . . . . . . . . . . . . ................... P. carabidophila Khaustov, 2005

- Setae $c_{1}, d, e$ and $f$ pointed; setae $v_{1}$ never reaching beyond bases of setae $c h_{1}$ (Ukraine). . . P. bembidii Khaustov, 2005

11 Setae $h_{2}$ more than twice as long as $h_{1}$; setae $e$ and $f$ subequal and both longer than $d$; setae $f$ distinctly longer than $c_{1}$ (Egypt).... . P. tahanae Sevastianov and Abo-Korah, 1985

- Setae $h_{2}$ less than twice as long as $h_{1}$; setae $e$ and $d$ subequal and both longer than $f$; setae $c_{1}$ and $f$ subequal (Russia, Turkmenistan, Iran). . . . . P. P. protracta Sevastianov, 1980

12 Setae $h_{2}$ more than 6 times longer than $h_{1} \ldots \ldots \ldots \ldots 13$

- Setae $h_{2}$ less than 6 times longer than $h_{1} \ldots \ldots \ldots \ldots 16$

13 Setae $s c_{2}$ at least 3.5 times longer than $v_{1}$; setae $f$ more than twice as long as $e$; setae $e$ longer than $v_{1}$ (Ghana).

- Setae $s c_{2}$ less than 2.5 times longer than $v_{1}$; setae $f$ less than twice as long as $e$; setae $e$ shorter than $v_{1} \ldots \ldots \ldots \ldots 14$

14 Setae $s c_{2}$ less than twice as long as $v_{1}$; setae $f$ longer than $d$; setae $c_{1}$ reaching beyond posterior border of tergite C (Brazil). . . . . . . . . . . . . . P. brasiliensis Mahunka, 1970

- Setae $s c_{2}$ more than twice as long as $v_{1}$; setae $f$ and $d$ subequal; setae $c_{1}$ never reaching beyond posterior border of tergite C. . . . . . . . . . . . . . . . . . . . . . 15

15 Setae $2 a$ as long as $2 c$ and both longer than $c_{1}, d$ and $f$; setae $s u$ protruding beyond anterior border of gnathosoma (Iran). . ............. P. elongata Hajiqanbar \& Khaustov sp. n.

- Setae $2 a$ longer than $2 c$ and both shorter than $c_{1}, d$ and $f$; setae $s u$ never protruding beyond anterior border of gnathosoma (Ghana). . . . . . . . . . . P. simplex Mahunka, 1973
16 Setae $e$ and $f$ subequal; setae $e$ longer than $h_{1}$; setae on epimeres II subequal (Tajikistan). . . . . . . . . . . . . . . ............... P. tadjikistanica Sevastianov, 1980 - Setae $f$ more than twice as long as $e$; setae $e$ and $h_{1}$ subequal; setae on epimeres II not subequal. . . . . . . . . . 17

17 Most dorsal idiosomal setae weakly barbed and blunt-ended; setae $c_{1}$ longer than $c_{2}$; setae $s c_{2}$ less than twice as long as $c_{1}$ (Iran). ........ P. kamalii Hajiqanbar \& Khaustov sp. n. - Dorsal idiosomal setae smooth and pointed; setae $c_{2}$ longer than $c_{1}$; setae $s c_{2}$ more than twice as long as $c_{1}$ (Italy). . . . . ................. P. fusiformis Lombardini, 1949

ACKNOWLEDGEMENTS. We are indebted to W.L. Magowski (Department of Animal Taxonomy and Ecology, A. Mickiewicz University, Poznan, Poland) for reviewing the manuscript and his valuable and helpful comments. We also express our gratitude to V. Martynov (Donetsk National University, Donetsk, Ukraine) for identifying the scarabaeid beetles. Special thanks go to A. Khurani (Department of Geography, Faculty of Humanity, Tarbiat Modares University, Tehran, Iran) for providing the distribution map of the genera, which was obtained using GIS software.

\section{REFERENCES}

Kaliszewski M., Athias-Binche F. \& Lindquist E.E. 1995: Parasitism and parasitoidism in Tarsonemina (Acari: Heterostigmata) and evolutionary considerations. Adv. Parasitol. 35: 335-367.

LINDQUIST E.E. 1986: The world genera of Tarsonemidae (Acari: Heterostigmata): A morphological, phylogenetic and systematic revision, with a reclassification of family-group taxa in Heterostigmata. Mem. Entomol. Soc. Can. 136: 1-517.

LindQuist E.E. \& KRANTZ G.W. 2002: Description of, and validation of names for the genus Crotalomorpha and the family Crotalomorphidae (Acari: Heterostigmata). Syst. Appl. Acarol. 7: 129-142.

Magowski W. 1997: Rafamastix plenus gen. n., sp. n. of the family Dolichocybidae from South America (Acari: Heterostigmata). Genus 8: 61-74.

Mironov S.V. \& BochKov A.V. 2009: Modern conceptions concerning the macrophylogeny of acariform mites (Chelicerata, Acariformes). Zool. Zh. 88: 922-937 [in Russian].

Sevastianov V.D. 1980: New taxa of mites of the family Dolichocybidae (Trombidiformes, Tarsonemina) and phylogenetic relations of its subfamilies. Zool. Zh. 59: 1453-1462 [in Russian].

Received August 20, 2009; revised and accepted February 17, 2010 